\title{
Evaluation of 3-D Printer Emissions and Personal Exposures at a Manufacturing
}

\section{Workplace}

\section{Aleksandr B. Stefaniak, PhD, CIH}

Duane R. Hammond, MS, PE

Alyson R. Johnson, MPH

Alycia K. Knepp, BSc Ryan F. LeBouf, PhD, CIH

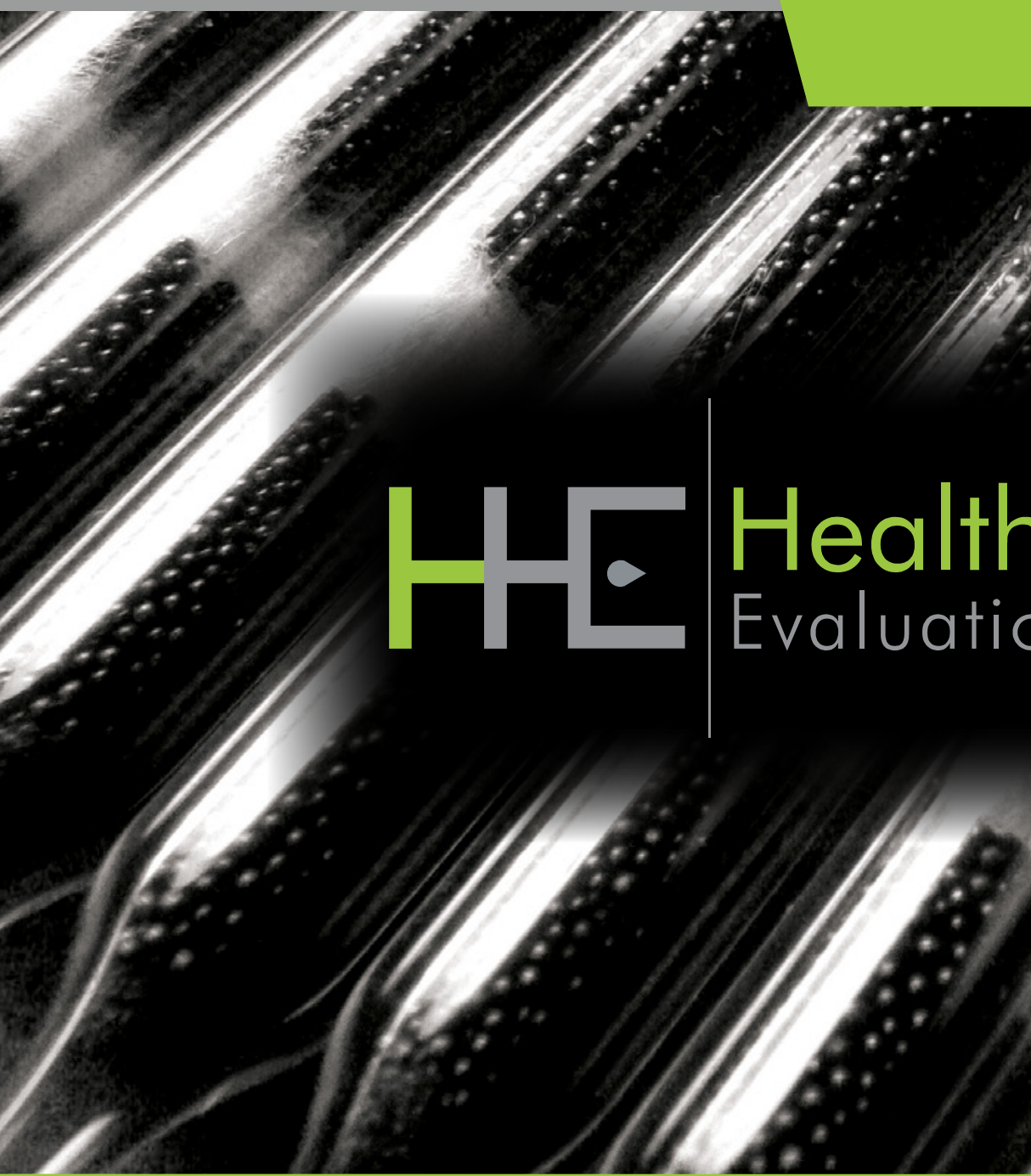

Report No. 2017-0059-3291

August 2017

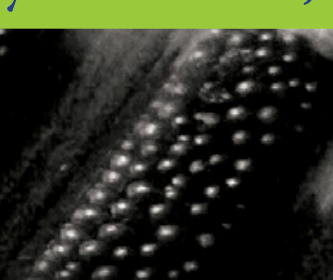




\section{Contents}

Highlights. i

Abbreviations ...................................... iv

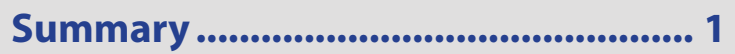

Introduction ...................................... 2

Background............................................. 2

Process Description ................................ 2

Methods ..................................................... 3

Results .................................................... 8

Discussion .......................................... 33

Conclusions......................................... 35

Recommendations............................ 36

References........................................ 38

Acknowledgements.......................... 42

The employer is required to post a copy of this report for 30 days at or near the workplace(s) of affected employees. The employer must take steps to ensure that the posted report is not altered, defaced, or covered by other material.

The cover photo is a close-up image of sorbent tubes, which are used by the HHE Program to measure airborne exposures. This photo is an artistic representation that may not be related to this Health Hazard Evaluation. 


\section{Highlights of this Evaluation}

The Health Hazard Evaluation Program received a management request from a facility that manufactures products using 3-dimensional printing. The owner was concerned about employee exposures to emissions from the 3-dimensional printers.

\section{What We Did}

- We visited the manufacturing facility in April 2017.

- We evaluated 3-dimensional printer emissions and measured personal exposures to printer workers.

- We evaluated different ways to reduce emissions from the 3-dimensional printers.

\section{What We Found}

- Particles and organic chemicals were emitted from the 3-dimensional printers when using poly lactic acid and acrylonitrile butadiene styrene filaments.

- Concentrations of particles and organic chemicals released by the 3-dimensional printers were similar when using poly lactic acid and acrylonitrile butadiene styrene filaments.

- Particles and organic chemicals emitted from the 3-dimensional printers do not infiltrate into the Engineer's Office.

We evaluated concerns that employees were exposed to particles and vapors at a manufacturing facility that utilizes 3-dimensional printing. We found that personal exposures were well below established regulatory limits for specific chemicals, though if changes are made to the existing process, the employer should reassess personal exposures and emissions.

- Loose-fitting doors and covers provided by the printer manufacturer did not prevent particles and organic vapors from being released into air in the Print Room.

- A custom-built ventilated enclosure effectively reduced particle concentration in the Print Room by over $99 \%$ and reduced the total organic chemical concentration by almost $70 \%$.

- Particles and organic chemicals were released into air during warm-up and use of the injection molding machine in the High Bay.

- Personal exposures occurred to organic chemicals though levels were all well below established regulatory limits.

\section{What the Employer Can Do}

- If changes are made to the existing process, the employer should reassess personal exposures and emissions. 


\section{What Employees Can Do}

- Close the door to the Engineer's Office when performing injection molding, grinding, or other tasks in the High Bay that generate particles and organic vapors.

- Be aware of how specific tasks influence exposures and that changes in how work is performed could increase exposure. 
This page left intentionally blank 


\section{Abbreviations}

$\mu \mathrm{m}$

ABS

ACGIH

$\mathrm{cm}^{3}$

$\mathrm{CNC}$

DC

$\mathrm{NIOSH}$

$\mathrm{nm}$

OEL

OPC

OSHA

PEL

PLA

ppb

ppm

REL

STEL

TLV

TWA

TVOC

$\mu \mathrm{g} / \mathrm{m}^{3}$

VOC
Micrometer

Acrylonitrile butadiene styrene

American Conference of Governmental Industrial Hygienists

cubic centimeter of air

Condensation nuclei counter

Diffusion charger

National Institute for Occupational Safety and Health

Nanometer

Occupational exposure limit

Optical particle counter

Occupational Safety and Health Administration

Permissible exposure limit

Poly lactic acid

Parts per billion

Parts per million

Recommended exposure limit

Short-term exposure limit

Threshold limit value

Time-weighted average

Total volatile organic chemicals

Micrograms per cubic meter of air

Volatile organic chemicals 


\section{Summary}

We evaluated volatile organic compound and particle emissions from fused deposition modeling ${ }^{\mathrm{TM}} 3$-D printers using poly lactic acid and acrylonitrile butadiene styrene thermoplastics and measured personal exposures to total and specific volatile organic compounds. The 3-dimensional printers emitted both volatile organic compounds and small particles during operation. Levels of all individual volatile organic compounds that were quantified on personal samples were well below applicable occupational exposure limits and guidelines. None of the employees reported any respiratory symptoms. At this time, we do not recommend any controls to lower exposures as they are already well-below established regulatory limits. Similarly, at this time we do not recommend the need to lower total particle number and total volatile organic chemical concentrations as there is no available guidance on appropriate levels. It is important to note that 3-D printing has not been thoroughly evaluated to determine its safety. As such, new information may become available in the future which may change our current perspective on the necessity of controls. 


\section{Introduction}

The Health Hazard Evaluation Program of the National Institute for Occupational Safety and Health (NIOSH) received a request from a facility that manufactures products using 3-dimensional (3-D) printing. The owner was concerned about employee exposures to particles and vapors that are emitted from fused deposition modeling ${ }^{\mathrm{TM}}$ 3-D printers using poly lactic acid (PLA) and acrylonitrile butadiene styrene (ABS) thermoplastics as well as injection molding with ABS thermoplastic. We visited the facility in April 2017 and measured levels of particles and organic chemicals in air and evaluated two different ways to reduce emissions from the 3-dimensional printers - use of the covers and doors provided by the printer manufacturer and use of a ventilated enclosure custom built by NIOSH.

\section{Background}

Additive manufacturing is a family of technologies used to build objects (usually layerby-layer) from a computer-assisted design computer file. At this facility, a specific type of additive manufacturing technology called fused deposition modeling ${ }^{\mathrm{TM}}$, more commonly known as 3-D printing, is used to make objects. In this technique, a polymer filament is heated and extruded through a nozzle onto a build plate to create an object. During heating, the polymer filament degrades and releases ultrafine particles (size less than 100 nanometers $[\mathrm{nm}])$ and organic chemicals into the air. There is growing interest in understanding the characteristics of these emissions. In particular, when breathed in, ultrafine particles are small enough to reach the deepest part of the lung where they can deposit. Once deposited in the lung, it is difficult for the body to efficiently remove these small particles. Breathing in small particles and some organic chemical vapors is associated with irritating the lungs or asthma [Yi et al. 2016; Stefaniak et al. 2017].

\section{Process Description}

The company operates in leased space that occupies one half of a single-level building. We estimate that the company operates in about 24,000 square feet and consists of a Print Room which houses the 3-D printers, a High Bay where post-processing tasks and injection molding are performed, and an Engineer's Office where computer work is performed. At this facility, 3-D printing is used to make cup holders with add-ons such as handles and clips and various other objects. PLA filament is primarily used at this facility, though ABS was also printed during our site visit as the company is considering its use in the future.

At the time of our visit, the company had two full-time employees, an Engineer and the owner, and several part-time interns that also worked in the facility. Employees worked varying hours throughout the day from Monday through Friday. The Print Room had a rectangular floor plan with a drop ceiling and linoleum flooring (volume of 1570 cubic feet). There were 10 "desktop-scale" 3-D printers arranged on shelves 2 high by 5 wide and one freestanding industrial-scale 3-D printer (not in use at the time of our survey). A recirculating wall-mounted air conditioning unit was in the print room but no ventilation. The High Bay had a rectangular floor plan with concrete flooring (volume of 20,000 cubic feet) and was isolated from the Print Room and Engineer's Office by a wall. The door between the High 
Bay and the Print Room remained closed; whereas, the door to the Engineer's Office was (usually) open. The High Bay contained several work benches which serve various purposes such as shipping area, post-processing of printed products, injection molding, and general machining. Post-processing tasks included sanding objects and "light" torching to brighten object colors. At the time of our survey, the company was exploring the feasibility of using a custom-built injection molding machine with ABS plastic to produce products. In the High Bay, there was only general ventilation for occupant comfort. The Engineer's Office was of the same construction as the Print Room but slightly smaller (volume of 1260 cubic feet) and contained two desks and a computer. The Engineer's Office and Print Room were separated by a wall that went from the floor to the drop ceiling but not to the building roof.

The full-time employees and interns designed objects on a computer in the Engineer's Office and communicated the build files to the 3-D printers. They entered the Print Room throughout the day for short periods of time to check on the status of prints, remove built products, or trouble shoot and fix problems if they arose. In the High Bay, employees manually sanded printed objects using an aluminum grit sandpaper and light torched printed objects using a butane torch to draw pigment colors out of the filament and brighten product color after sanding. Additionally, the owner operated the injection molding machine on an asneeded basis. Once finished, products were packaged for shipment.

\section{Methods}

Our primary objectives were to evaluate:

1. chemical and particle emissions from the desktop-scale 3-D printers under normal work conditions with PLA filament;

2. whether emissions changed if printing with ABS filament;

3. if emissions from the Print Room infiltrated into the Engineer's Office;

4. whether the manufacturer-provided covers and doors of the 3-D printers were effective in reducing emissions;

5. whether a ventilated enclosure system with filtration was effective in reducing emissions;

6. the influence of post-processing tasks and injection molding on emissions; and,

7. employees' exposures to volatile organic chemicals (VOCs).

To achieve these objectives, we performed air sampling for airborne particles and/or organic vapors during 3-D printing and during specific tasks (e.g., sanding, torching, injection molding) and observed work practices over three days.

\section{Air sampling for particles in general workplace air}

We evaluated airborne particles in each work area using two types of techniques, the first is referred to as "real-time" monitoring and the second is called "time-integrated" sampling. For real-time monitoring, we used instruments that measure the particles very rapidly (one second to one minute intervals) and visually display the results on the instrument. The 
measurement data is also stored on an internal memory for analysis at a later time. Real-time instruments have the advantage of performing measurements quickly, which allowed us to identify specific emission sources (3-D printers) and see how changes in processes or tasks influenced the characteristics of particles in the air. A disadvantage of real-time instruments is that they measure all particles and cannot tell us if they were emitted from a specific source such as the 3-D printers. In time-integrated sampling, air is drawn through a filter for a period of time to collect particles. The filter is later analyzed in a laboratory to determine the properties of the collected particles. A major advantage of time-integrated sampling is that we can visualize the particles on the filter, which can be helpful to determine if airborne particles have size and shape consistent with emissions from the 3-D printers.

Table 1 summarizes the real-time instruments used to monitor airborne particles in each work area. We measured particle number concentration using a condensation nuclei counter (CNC) (Model 8525, TSI Inc., Shoreview, MN), particle size distribution using an optical particle counter (OPC) (Model 1.108, GRIMM Aerosol Technik GmbH \& Co. Ainring, Germany) or a mobility analyzer (Nanoscan) (Model 3910, TSI Inc., Shoreview, USA), and particle surface area using a diffusion charger (DC) (Model DC 2200 CE, EcoChem Analytics, League City, TX).

Table 1. Real-time air monitoring instruments for particles

\begin{tabular}{ll}
\hline \multicolumn{1}{c}{ Instrument } & \multicolumn{1}{c}{ What it measures } \\
\hline Optical particle counter (OPC) & Number and size of particles from $300 \mathrm{~nm}$ to $>20 \mu \mathrm{m}$ \\
Condensation nuclei counter (CNC) & Number of particles from 20 to $1000 \mathrm{~nm}$ \\
Mobility analyzer (NanoScan) & Number and size of particles from 10 to $420 \mathrm{~nm}$ \\
Diffusion charger (DC) & Surface area of particles \\
\hline
\end{tabular}

We performed time-integrated sampling for airborne particles using 37-millimeter diameter track-etched polycarbonate filters with $0.8 \mu \mathrm{m}$ pore size (SKC Inc., Eighty Four, PA) mounted in close-faced 37 millimeter plastic cassettes by drawing air through the membrane at 2 liters per minute using calibrated sampling pumps. We analyzed the filters at NIOSH using a field emission-scanning electron microscope to evaluate size and shape of particles. This microscopy is able to visualize particles with sizes less than $100 \mathrm{~nm}$. We also used a technique called energy dispersive $\mathrm{x}$-ray analysis to determine the chemical elements in collected particles.

Air sampling for organic chemicals in general workplace air We evaluated organic chemicals in air using real-time monitoring instruments and timeintegrated sampling. We used a real-time monitor to rapidly measure the concentrations of organic chemicals in air, but it could not identify which specific chemicals were present. As such, a time-integrated sampler was used to collect air in a canister. The canister was transported back to NIOSH for analysis in our laboratory to identify specific chemicals and their concentrations.

We measured real-time total volatile organic chemical (TVOC) concentrations using a 
photoionization detector (RAE Systems, San Jose, USA or Ion Science Inc., Stafford, TX) to monitor fluctuations in organic chemical levels during specific activities and work tasks. The TVOC monitors were factory calibrated using isobutylene gas and span checked with isobutylene gas prior to use. We collected air samples using 450 milliliter Silonite ${ }^{\circledR}$ coated evacuated canister (Entech Instruments, Simi Valley, CA) samplers over a period of 6 hours (in work areas) or over 30 seconds (during specific tasks) to quantify specific VOCs. We analyzed air collected in the canister samplers at NIOSH using a pre-concentrator/gas chromatograph/mass spectrometer system pursuant to a published method validation study [LeBouf et al. 2012] but modified to use a Model 7200 (Entech Instruments, Inc., Simi Valley, CA) pre-concentrator. All quantitative measurement results were corrected for the concentration of VOCs measured on background samples collected in workplaces.

\section{Environmental conditions in general workplace air}

We monitored general environmental conditions in each work area using two real-time instruments. We used a gas sensitive semiconductor sensor (Model S500, Ozone Solutions, Hull, IA) to monitor ozone concentrations and an environmental monitor (Velocicalc, Model 9565, TSI Inc.) to monitor temperature and carbon dioxide and carbon monoxide levels.

\section{Sampling locations}

We monitored air and collected samples in the Print Room, Engineer's Office, and the High Bay. For each work area on each day, we placed the real-time monitors and time-integrated samplers in a basket attached to a tripod (Figure 1) and positioned at the approximate height of a worker's head. The tripod in the Engineer's Office was designated Location 1. We placed two tripods in the Print Room; the first was next to the 3-D printers and designated Location 2 , and the other was just inside the doorway to the room and referred to as Location 3. We used individual instruments and samplers to evaluate tasks at different locations in the High Bay. 


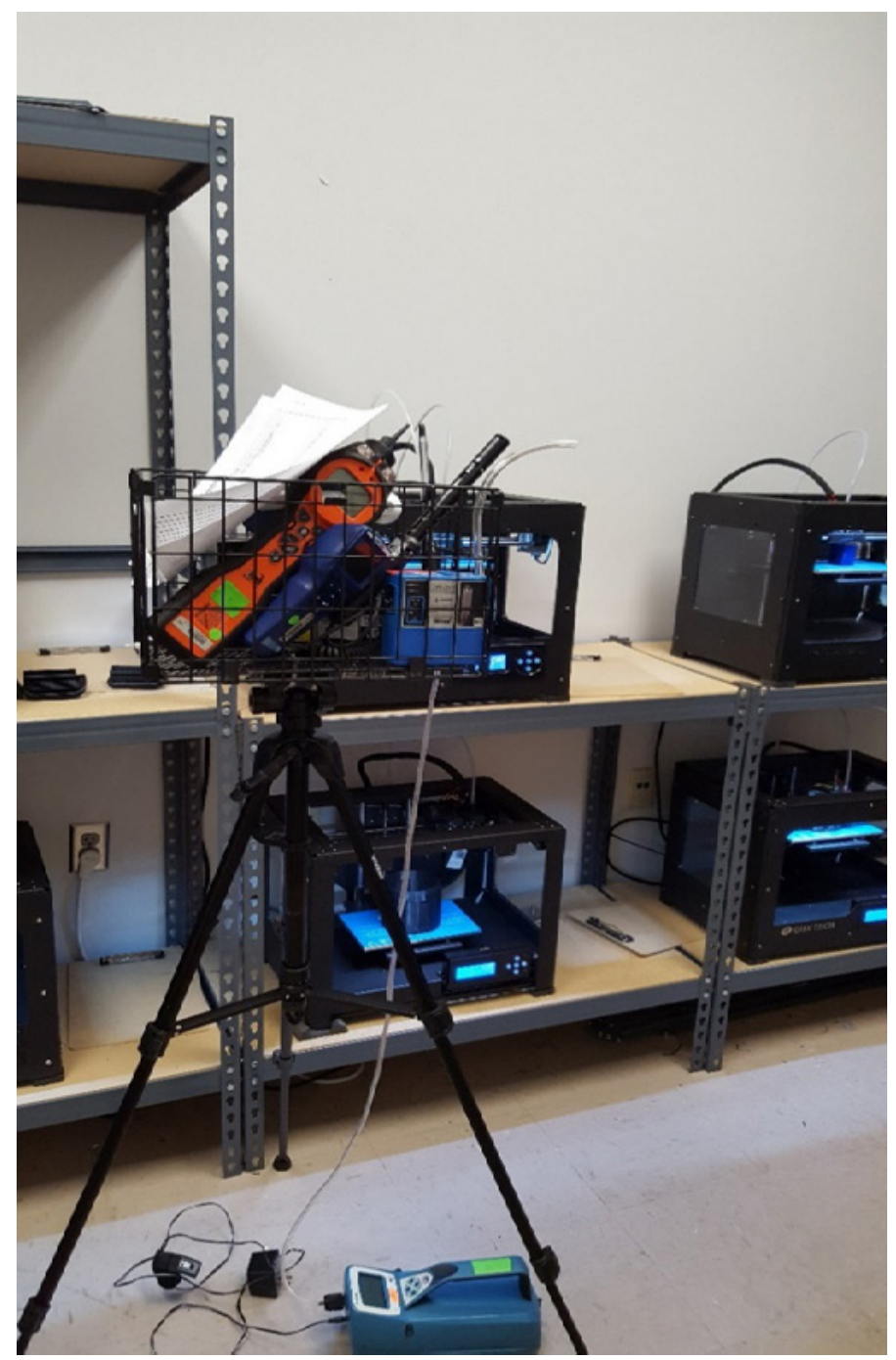

Figure 1. Area sampling station showing real-time monitors and time-integrated samplers in the Print Room. Photo by NIOSH.

\section{Personal exposure monitoring}

We collected two samples each day to evaluate the Engineers' personal exposures to VOC vapors. Samples were collected from the workers' breathing zone (near the head). We evaluated TVOC levels using a real-time photoionization detector (Cub personal VOC detector, Ion Science Inc.) and observed work activities to understand the contribution of work to exposures. Additionally, we collected 450 milliliter evacuated canister samplers over a period of 6 hours for laboratory analysis to identify specific VOCs as described previously. Additionally, at the end of the work shift, we administered a questionnaire asking employees if they experienced any respiratory symptoms and other symptoms at work.

NIOSH investigators refer to mandatory (legally enforceable) and recommended occupational exposure limits (OELs) for chemical, physical, and biological agents when evaluating workplace hazards. OELs have been developed by federal agencies and safety and health organizations to prevent adverse health effects from workplace exposures. Generally, OELs suggest levels of exposure that most employees may be exposed to for up to 8-10 
hours per day, 40 hours per week, for a working lifetime, without experiencing adverse health effects. However, not all employees will be protected if their exposures are maintained below these levels. Some may have adverse health effects because of individual susceptibility, a pre-existing medical condition, or a hypersensitivity (allergy). In addition, some hazardous substances act in combination with other exposures, with the general environment, or with medications or personal habits of the employee to produce adverse health effects. Most OELs address airborne exposures, but some substances can be absorbed directly through the skin and mucous membranes.

Most OELs are expressed as a TWA exposure. A TWA refers to the average exposure during a normal 8- to 10-hour workday. Some chemical substances and physical agents have recommended short-term exposure level (STEL) or "ceiling" values. Unless otherwise noted, the STEL is a 15-minute TWA exposure. It should not be exceeded at any time during a workday. The ceiling limit should not be exceeded at any time.

In the United States, OELs have been established by the Occupational Safety and Health Administration (OSHA). The U.S. Department of Labor OSHA permissible exposure limits (PELs) (29 CFR 1910 [general industry]; 29 CFR 1926 [construction industry]; and 29 CFR 1917 [maritime industry]) are legal limits. These limits are enforceable in workplaces covered under the Occupational Safety and Health Act of 1970. OSHA PELs represent the legal maximum for a TWA exposure to a physical or chemical agent over a work shift [OSHA 2016]. OSHA STELs are the legal maximum average exposure for a 15-minute time period. Some chemicals also have an OSHA ceiling value which represent levels that must not be exceeded at any time.

NIOSH recommended exposure limits (RELs) are recommendations based on a critical review of the scientific and technical information and the adequacy of methods to identify and control the hazard. NIOSH RELs are published in the NIOSH Pocket Guide to Chemical Hazards [NIOSH 2010]. NIOSH also recommends risk management practices (e.g., engineering controls, safe work practices, employee education/training, personal protective equipment, and exposure and medical monitoring) to minimize the risk of exposure and adverse health effects. NIOSH provides REL values as TWA concentrations that should not be exceeded over an 8- or 10-hour work shift, during a 40-hour workweek [NIOSH 2010]. NIOSH also provides STELs which are 15-minute TWA exposures that should not be exceeded [NIOSH 2010].

Other OELs commonly used and cited in the United States include threshold limit values (TLVs ${ })$ which are recommended by the American Conference of Governmental Industrial Hygienists (ACGIH). ACGIH is a professional, not-for-profit scientific association that reviews existing published, peer-reviewed scientific literature and publishes recommendations for levels of substances in air based on an 8-hour workday and 40-hour workweek. These recommendations are called TLVs [ACGIH 2016]. ACGIH TLVs are not standards; they are health-based guidelines derived from scientific and toxicological information. ACGIH provides TLV-TWA guidelines that are levels that should not be exceeded during any 8-hour workday of a 40-hour workweek. ACGIH also provides TLV- 
STEL guidelines which are 15-minute exposure levels that should not be exceeded during a workday. Exposures above the TLV-TWA but less than the TLV-STEL should be (1) less than 15 minutes, (2) occur no more than four times a day, and (3) be at least 60 minutes between exposures [ACGIH 2016]. Additionally, ACGIH provides TLV-Ceiling values which are levels that should not be exceeded at any time during a work shift.

OSHA requires an employer to furnish employees a place of employment free from recognized hazards that cause or are likely to cause death or serious physical harm [Occupational Safety and Health Act of 1970 (Public Law 91-596, sec. 5(a)(1))]. This is true in the absence of a specific OEL. It also is important to keep in mind that OELs may not reflect current health-based information.

The results of the personal canister samples are compared to the OSHA PELs, NIOSH RELs, and ACGIH TLVs. Area samples for particles and TVOCs were collected to identify specific emission sources (3-D printers) and see how changes in processes or tasks influenced the characteristics of particles in the air. For all area samples of workplace air, it is not appropriate to compare results to these OELs. Note that for some measurements such as particle number, size, and surface area and TVOC concentration there are no recognized OELs to which the results can be compared to determine if they are safe. However, we included this data in our report so that the company can see how specific 3-D printing parameters and work tasks influence their release into workplace air.

\section{Results}

\section{Objective 1: Evaluation of emissions during 3-D printing with PLA filament}

We collected samples in the Print Room to evaluate particle and chemical emissions from the 3-D printers under normal work conditions with PLA filament on two different days and overnight. During both days, objects were printed using white, black, dark blue, yellow, and/ or wood colored PLA filaments. Depending on the time of day, print job duration, and other factors, from 8 to 10 of the 3-D printers were in operation.

\section{Particle concentrations in the Print Room during the day}

The OPC and DC instruments used to monitor air in the Print Room were both placed at Location 2 (adjacent to the printers). The concentration of particles with sizes from $300 \mathrm{~nm}$ to greater than $20 \mu \mathrm{m}$ did not exceed 100 particles per cubic centimeter of air $\left(\mathrm{cm}^{3}\right)$ on either day. Particle surface area concentration increased throughout the morning from about 50 square millimeters of surface per cubic meter of air $\left(\mathrm{mm}^{2} / \mathrm{m}^{3}\right)$ to about $250 \mathrm{~mm}^{2} / \mathrm{m}^{3}$ by midday and decreased thereafter.

CNC instruments were placed at both Location 2 (adjacent to the 3-D printers) and Location 3 (just inside the door of the Print Room). On the first day, the number concentration of particles at both locations ranged from 50,000 to 200,000 particles/ $\mathrm{cm}^{3}$ of air (see Figure 2). A similar concentration pattern was observed on the second day. The high particle number concentrations measured with the $\mathrm{CNC}$ instruments compared to the OPC indicated that 
particles emitted from the 3-D printers generally have small size. Note that on the first day, at Location 2, particle number concentration exceeded 450,000 particles $/ \mathrm{cm}^{3}$ of air on two occasions; these peaks at 144 minutes and 164 minutes corresponded to times when we placed the CNC monitor inlet near the open top of the same printer using white PLA. At 220 minutes, we monitored that same printer, but when it was using black PLA, and there was no peak, which provided further evidence that white PLA was responsible for these increases in emitted particles.

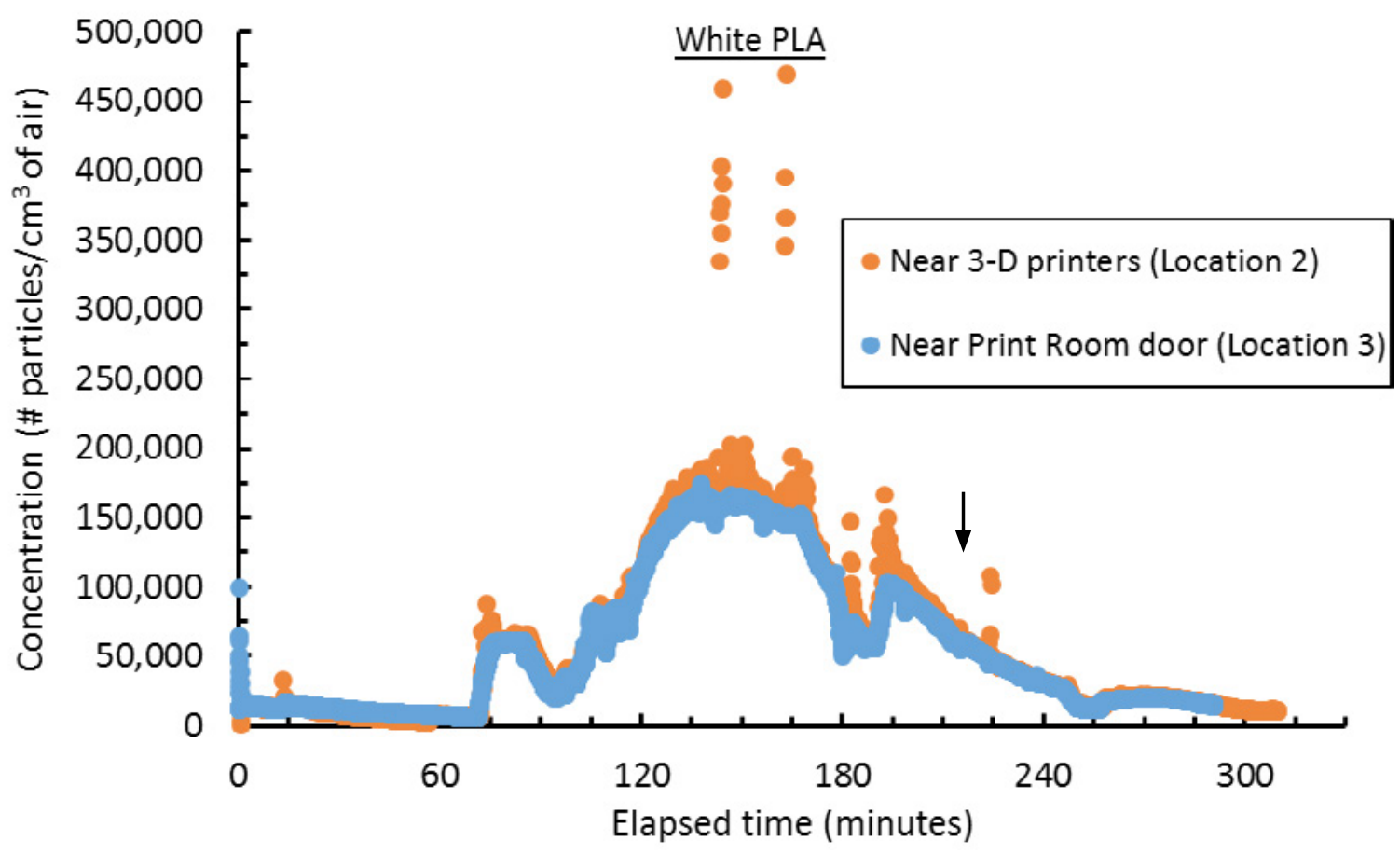

Figure 2. Particle number concentration in the Print Room while printing only with PLA filaments. The two peaks were from the same printer using white PLA. The arrow indicates the absence of a peak when that printer was using black PLA. 
Figure 3 shows high magnification pictures of particles collected on filters in the Print Room and illustrate the small size of airborne particles released during 3-D printing with PLA filament. The particles are clusters of many small particles; the filter pores are the dark circles and the filter itself is the light gray background. Analysis of the particle chemistry determined that the particles were made up of iron and/or carbon which is typical of PLA emissions.
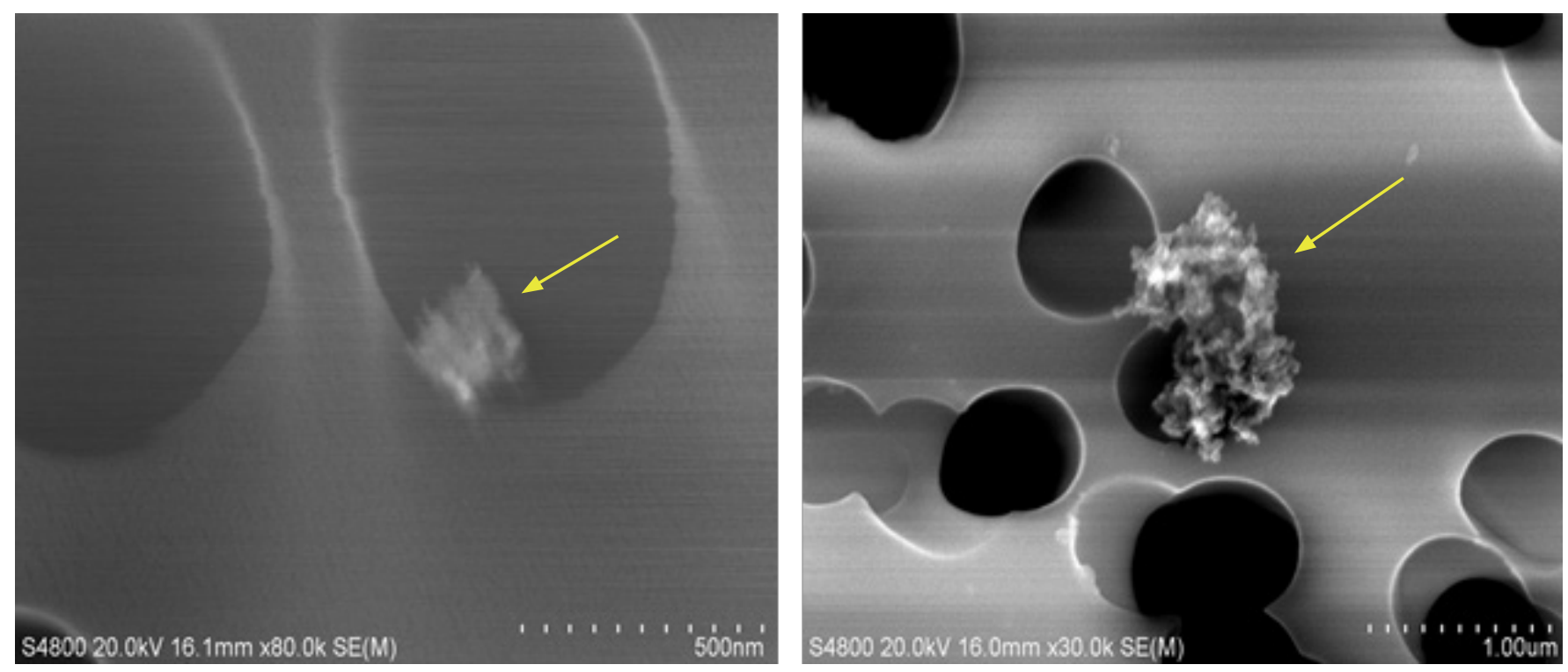

Figure 3. High magnification images of particles (denoted by yellow arrows) emitted from a 3-D printer while printing only with PLA filaments at Location 2 (left image) and Location 3 (right image). Images by NIOSH.

Figure 4 is a plot of particle size distribution measured in the Print Room on the first day using the NanoScan monitor. As shown in the plot, the average particle size is about $44 \mathrm{~nm}$. On the second day, the average particle size was $40 \mathrm{~nm}$.

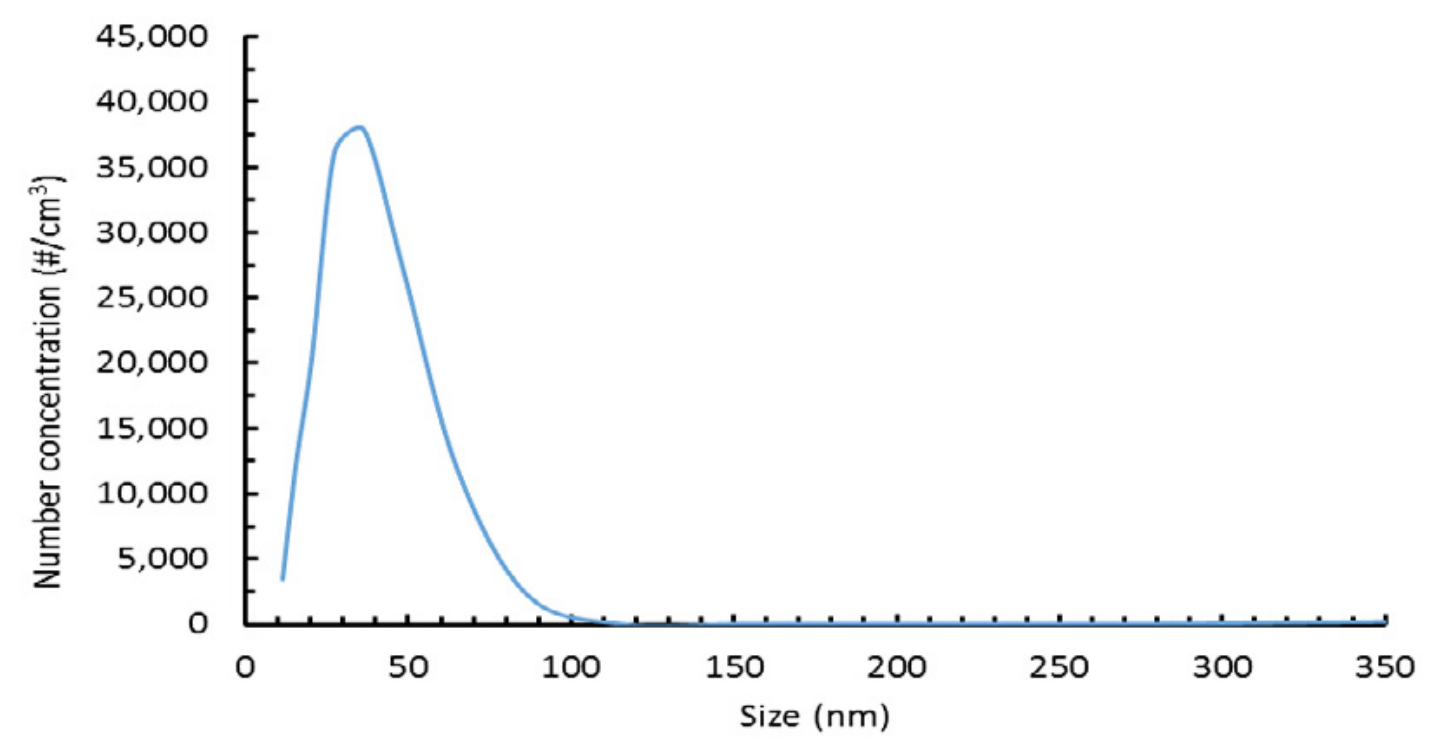

Figure 4. Particle size distribution in the Print Room while during the day while printing only with PLA filaments. The average particle size was about $44 \mathrm{~nm}$. 
Volatile organic chemical concentrations in the Print Room during the day

We measured the real-time TVOC concentrations at both Location 2 and 3 (see Figure 5). On the first day, concentrations were initially about 2,000 micrograms $(\mu \mathrm{g})$ per cubic meter of air $\left(\mathrm{m}^{3}\right)$ but increased to $12,000 \mu \mathrm{g} / \mathrm{m}^{3}$ at Location 2 and $9,000 \mu \mathrm{g} / \mathrm{m}^{3}$ at Location 3 as printers operated. At both locations, TVOC levels had a "saw tooth" pattern which is consistent with the starting and stopping of 3-D print jobs throughout the day. We observed similar concentration levels and patterns on the second day of monitoring.

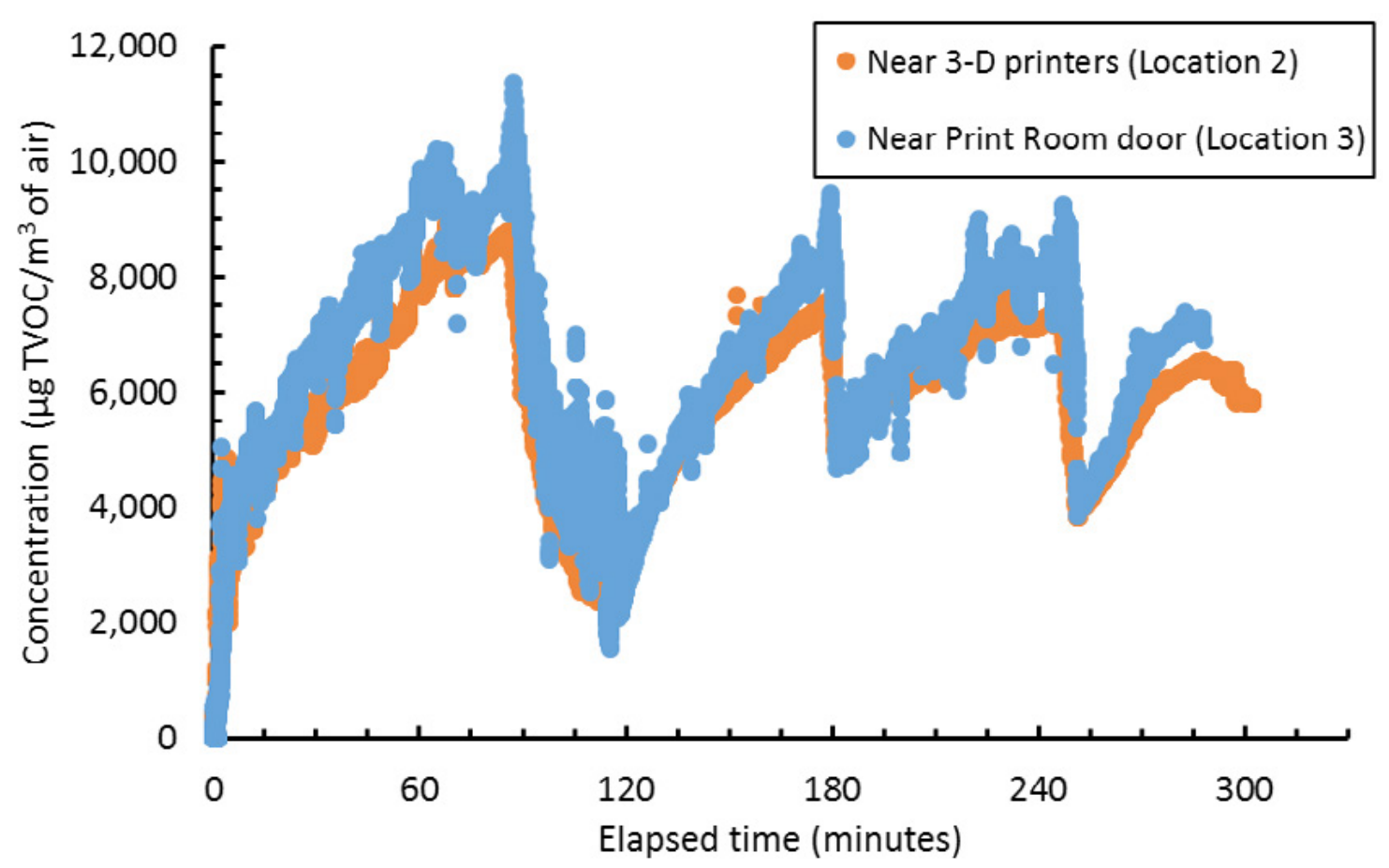

Figure 5. Total organic vapor concentrations in the Print Room while printing only with PLA filaments.

We collected canister samples at both locations in the Print Room to identify and quantify individual organic chemicals. Table 2 summarizes the results of the canister samples. Generally, concentrations were similar between locations indicating that contaminants were mixed throughout the room. Acetaldehyde, acetone, ethanol, isopropyl alcohol, and toluene are known to be emitted during printing with PLA filaments [Stefaniak et al. 2017]. Though the canister method we used is not fully validated, the presence of diacetyl and 2,3-pentanedione are of interest as these chemicals are often used as ingredients in flavorings and are known respiratory hazards [NIOSH, 2016]. Diacetyl and 2,3-pentanedione are types of chemicals referred to as "carbonyl" compounds which is a family of compounds with similar chemical structures. Based on our previous studies of 3-D printing, using experimental sampling methods, we determined that some chemicals emitted during printing can react with ozone in air to form carbonyl compounds [Stefaniak et al. 2017]. As such, it is likely that diacetyl and 2,3-pentanedione were not emitted by the printing process but were formed in air from the reaction of ozone and other organic chemicals. 
Table 2. Concentrations of organic chemicals in the Print Room while printing only with PLA filaments (all values in ppb)

\begin{tabular}{lrrrr}
\hline \multirow{2}{*}{ Chemical } & \multicolumn{2}{c}{ Location 2 } & \multicolumn{2}{c}{ Location 3 } \\
\cline { 2 - 5 } & \multicolumn{1}{c}{ Day 1 } & Day 2 & Day 1 & \multicolumn{1}{c}{ Day 2 } \\
\hline Acetaldehyde & 46.2 & 23.9 & 40.1 & 18.7 \\
Acetone & 93.5 & 114.9 & 110.7 & 92.5 \\
Benzene & & 3.5 & & \\
Diacetyl & 1.0 & & 0.5 & 2.9 \\
2,3-pentanedione & & & & 0.9 \\
Ethanol & 21.4 & & 21.8 & 16.0 \\
Isopropyl Alcohol & 9525 & 16584 & 13621 & 14500 \\
Methyl Methacrylate & 0.9 & 1.1 & & 1.3 \\
Methylene Chloride & 1.8 & 2.6 & 1.6 & 3.0 \\
Toluene & 1.1 & & & 0.7 \\
m,p-Xylene & 1.1 & & & 0.6 \\
\hline
\end{tabular}

Empty cell $=$ chemical not detected

\section{Environmental conditions in the Print Room}

Environmental measurements were only made at Location 2 . The average ozone concentration was 27 parts per billion (ppb) but reached a maximum of $60 \mathrm{ppb}$. Levels of carbon dioxide ranged from 600 parts per million (ppm) to $1300 \mathrm{ppm}$ and levels of carbon monoxide were less than $2.5 \mathrm{ppm}$. Average temperature in the Print Room was $78^{\circ} \mathrm{F}$.

\section{Overnight Sampling in the Print Room}

At this facility, the 3-D printers were operated 24 hours a day. We monitored particles, TVOC concentrations, and environmental conditions in the Print Room during the overnight hours (approximately 6:00 pm to 10:00 am) on two occasions while the 3-D printers used PLA filaments. The purpose of this sampling was to determine if there was buildup of these contaminants in the Print Room overnight.

We placed the OPC and DC instruments in the Print Room at Location 2. The concentration of particles with sizes from $300 \mathrm{~nm}$ to greater than $20 \mu \mathrm{m}$ was less than 200 particles $/ \mathrm{cm}^{3}$ of air during either night. During both nights, particle surface area concentration decreased with time. We placed $\mathrm{CNC}$ instruments at Locations 2 (near the 3-D printers) and 3 (near the Print Room door). At both locations, particle number concentrations followed the same pattern and reached a maximum of 60,000 particles $/ \mathrm{cm}^{3}$ of air during the first night and 74,000 particles/ $\mathrm{cm}^{3}$ during the second night.

The TVOC concentration patterns at Locations 2 and 3 in the Print Room were the same during the overnight hours. During the first night, TVOC levels reached a maximum of 6,000 $\mu \mathrm{g} / \mathrm{m}^{3}$ of air and during the second night TVOC levels reached $12,000 \mu \mathrm{g} / \mathrm{m}^{3}$ of air. 
The maximum ozone concentration on either night was $62 \mathrm{ppb}$. Levels of carbon dioxide were below $1400 \mathrm{ppm}$, and carbon monoxide were less than $1.5 \mathrm{ppm}$.

\section{Objective 2: Evaluation of emissions during 3-D printing with ABS filament}

During this test, seven printers used PLA filaments (black, wood, or yellow) and three printers used ABS filament (white). As summarized in Table 3, during the time in which the three printers were operated with ABS and the other 7 were operated with PLA, there did not appear to be any difference in particle or chemical emissions compared to when all printers were operated with PLA on the prior days. All measurements were made at Location 2.

Table 3. Maximum values for particles, vapors, and gases measured while printing with ABS and PLA filaments versus only PLA filaments

\begin{tabular}{lcc}
\hline \multicolumn{1}{c}{ Measurement } & 3 ABS/7 PLA & 10 PLA \\
\hline Number of particles $[0.3$ to $>20 \mu \mathrm{m}], \# / \mathrm{cm}^{3}$ & 10 & 100 \\
Number of particles [20 to $1000 \mathrm{~nm}], \# / \mathrm{cm}^{3}$ & 80,000 & 200,000 \\
Size, $\mathrm{nm}$ & 48 & 44 \\
Surface area of particles, $\mathrm{mm}^{2} / \mathrm{cm}^{3}$ & 100 & 250 \\
Total organic chemicals, $\mu \mathrm{g} / \mathrm{cm}^{3}$ & 15,000 & 12,000 \\
Ozone, ppb & 55 & 60 \\
Carbon dioxide, ppm & 1000 & 1300 \\
Carbon monoxide, $\mathrm{ppm}$ & 1 & 2.5 \\
\hline
\end{tabular}

We collected canister samples at Locations 1 and 2 in the Print Room on the day in which printing was performed with both ABS and PLA filaments to identify and quantify individual organic chemicals. Table 4 summarizes the canister sampling results. Concentrations varied by location, and only half the chemicals were identified at both locations. Compared to Table 2 (printing with PLA only), the identities and concentrations of chemicals were similar. One notable exception was the concentration of isopropyl alcohol. The high concentrations of isopropyl alcohol were likely not from the ABS filament. On this day, an intern was cleaning the build platform of a printer with isopropyl alcohol for approximately 40 minutes, which resulted in a higher concentration of this chemical in air. 
Table 4. Concentrations of organic chemicals in the Print Room while printing with ABS (3 printers) and PLA (7 printers)

\begin{tabular}{lcc}
\hline \multirow{2}{*}{\multicolumn{1}{c}{ Chemical }} & \multicolumn{2}{c}{ Concentration $(\mathrm{ppb})$} \\
\cline { 2 - 3 } & Location 2 & Location 3 \\
\hline Acetaldehyde & 26.7 & 21.8 \\
Acetone & 146.3 & 157.4 \\
Diacetyl & 1.4 & 0.5 \\
2,3-Pentanedione & 1.2 & 0.6 \\
Ethanol & 24.6 & 16.4 \\
Isopropyl Alcohol & 34,050 & 18,425 \\
Methyl Methacrylate & 0.8 & 1.2 \\
Methylene Chloride & 1.5 & 2.5 \\
Toluene & 1.5 & 1.8 \\
m,p-Xylene & 0.8 & 0.6 \\
o-Xylene & & 0.3 \\
\hline
\end{tabular}

Empty cell $=$ chemical not detected

Objective 3: Determine if emissions from the Print Room infiltrate into the Engineer's Office

To evaluate if entrainment was occurring, we measured concentrations of particles and organic chemical in the Print Room and the Engineer's Office using real-time monitors on each day and overnight. Table 5 summarizes the maximum concentrations of particles, organic chemicals, and gases measured in the Engineer's Office and the Print Room over three days. Concentrations of particles with size $20 \mathrm{~nm}$ to $1000 \mathrm{~nm}$ in the Engineer's Office were between 6,000 and $18,000 / \mathrm{cm}^{3}$ on the first two days and up to $87,000 / \mathrm{cm}^{3}$ on the third day. As noted in the background section of this letter, the door to the Engineer's Office was usually open to the High Bay, and this maximum particle concentration corresponded to the time during which grinding and injection molding were being performed in the High Bay. Levels of organic vapors and carbon dioxide were lower in the Engineer's Office compared to the Print Room. The level of carbon monoxide was similar in the two rooms.

Table 5. Maximum daytime values for particles, vapors, and gases in the Engineer's Office and Print Room

\begin{tabular}{lccc}
\hline & & \multicolumn{2}{c}{ Print Room } \\
\cline { 3 - 4 } \multicolumn{1}{c}{ Measurement } & Engineer's Office & Location 2 & Location 3 \\
\hline Number of particles [20 to $1000 \mathrm{~nm}], \# / \mathrm{cm}^{3}$ & 87,000 & 450,000 & 270,000 \\
Total organic chemicals, $\mu \mathrm{g} / \mathrm{cm}^{3}$ & 50,000 & 64,400 & 72,000 \\
Carbon dioxide, $\mathrm{ppm}$ & 800 & 1800 & 1750 \\
Carbon monoxide, $\mathrm{ppm}$ & 2 & 2.5 & 2 \\
\hline
\end{tabular}


Figure 6 is a high magnification image of a particle collected on a filter in the Engineer's Office that illustrates the large size of airborne particles in that room. Unlike the particles in the Print Room, this particle has a compact morphology. Analysis of the particle chemistry determined that it was composed of iron, calcium, magnesium, aluminum, and silica and is most likely sand or other naturally occurring dust that was brought into the facility from outside.

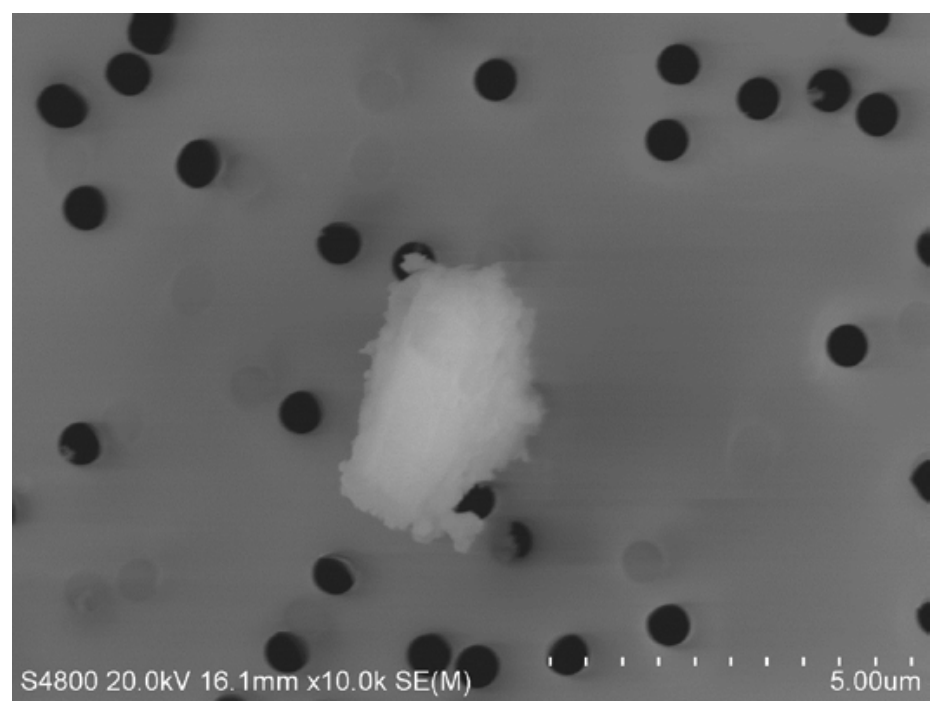

Figure 6. High magnification image of a particle collected in the Engineer's Office. Image by NIOSH.

We also collected canister samples in the Engineer's Office on each day and results are summarized in Table 6. Comparison of these results to Table 2 (PLA filaments) and Table 4 (PLA and ABS filaments) reveals that five chemicals were common to the Engineer's Office and the Print Room (acetaldehyde, acetone, ethanol, isopropyl alcohol, and toluene). Concentrations of acetaldehyde and isopropyl alcohol were relatively lower in the Engineer's Office, but levels of acetone, ethanol, and toluene were similar. Six chemicals were identified and quantified in the Print Room (diacetyl, 2,3-pentanedione, methyl methacrylate, methylene chloride, m,p-xylene, and o-xylene) but not in the Engineer's Office.

Table 6. Concentrations of organic chemicals in the Engineer's Office during three different days

\begin{tabular}{lccc}
\hline & \multicolumn{3}{c}{ Concentration $(\mathrm{ppb})$} \\
\cline { 2 - 4 } \multicolumn{1}{c}{ Chemical } & Day 1 & Day 2 & Day 3 \\
\hline Acetaldehyde & 4.1 & 6.9 & 11.4 \\
Acetone & 26.0 & 32.1 & 516.7 \\
Benzene & & 2.2 & \\
Ethanol & 17.4 & 16.0 & 26.5 \\
Isopropyl Alcohol & 1376 & 2266 & 5723 \\
Toluene & & 2.3 & 1.0 \\
\hline
\end{tabular}

Empty cell $=$ chemical not detected 
We measured levels of particles, organic chemicals, and gases overnight in the Engineer's Office and the Print Room on two occasions (see Table 7). Concentrations of particles with size $20 \mathrm{~nm}$ to $1000 \mathrm{~nm}$, and carbon dioxide levels in the Engineer's Office were much lower than in the Print Room. Interestingly, TVOC levels were higher in the Engineer's Office than in the Print Room on both nights. We were not present in the facility overnight so it is unknown what caused this increased concentration of organic vapors. Finally, levels of carbon monoxide were similar in all locations.

Table 7. Maximum overnight concentration values for particles, vapors, and gases measured while printing with ABS and PLA filaments or PLA filaments only

\begin{tabular}{lccc}
\hline & & \multicolumn{2}{c}{ Print Room } \\
\cline { 3 - 4 } Measurement & Engineer's Office & Location 2 & Location 3 \\
\hline Number of particles [20 to $1000 \mathrm{~nm}], \# / \mathrm{cm}^{3}$ & 11,230 & 74,900 & 61,900 \\
Total organic chemicals, $\mu \mathrm{g} / \mathrm{cm}^{3}$ & 14,273 & 7,669 & 5,613 \\
Carbon dioxide, $\mathrm{ppm}$ & 830 & 1478 & 1460 \\
Carbon monoxide, $\mathrm{ppm}$ & 1.5 & 0.8 & 0.1 \\
\hline
\end{tabular}

Table 8 summarizes the canister sample results for the Engineer's Office and the Print Room over two different nights. Eight chemicals were common to all locations, and except for toluene, levels were always higher in the Print Room. Six chemicals were identified and quantified in the Print Room but not in the Engineer's Office. Three of these chemicals were carbonyl compounds (diacetyl, 2,3-hexanedione and 2,3-pentanedione). As mentioned previously, using experimental methods, it is believed that these compounds were formed by reaction of printer emissions with ozone, not emitted by the 3 -D printers.

Table 8. Maximum overnight concentrations of organic chemicals in the Engineer's Office and Print Rooms

\begin{tabular}{lccc} 
& & \multicolumn{2}{c}{ Print Room } \\
\cline { 3 - 4 } \multicolumn{1}{c}{ Chemical } & Engineer's Office & Location 2 & Location 3 \\
\hline Acetaldehyde & 7.4 & 36.9 & 26.7 \\
Acetone & 42.2 & 163.5 & 137.3 \\
Benzene & & & 0.8 \\
Diacetyl & & 13.3 & 5.2 \\
2,3-Hexanedione & & & 4.1 \\
2,3-Pentanedione & 10.6 & 6.0 & 3.5 \\
Ethanol & & 23.6 & 134.6 \\
Ethylbenzene & 6351 & & 2.1 \\
Isopropyl Alcohol & 0.6 & 9504 & 9479 \\
Methyl Methacrylate & 0.9 & 1.7 & 3.5 \\
Methylene Chloride & & 7.7 & 8.0 \\
Styrene & 7.1 & 0.9 & 1.1 \\
Toluene & 0.6 & 0.6 & 2.4 \\
m,p-Xylene & & 0.5 & 2.6 \\
o-Xylene & & & 1.5 \\
\hline
\end{tabular}

Empty cell $=$ chemical not detected 
Objective 4: Effectiveness of the printer cover and doors to reduce emissions during 3-D printing

We collected samples in the Print Room to evaluate whether the manufacturer-provided covers and doors of the 3 -D printers are effective in reducing emissions. Throughout the day, objects were printed using black ( 7 printers), wood ( 2 printers), and yellow (1 printer) colored PLA filaments. Depending on the time of day, print job duration, and other factors, from 2 to 10 of the 3 -D printers were in operation.

Particles and organic chemicals in air were monitored in the Print Room under normal operating conditions from 11:00 am until 3:00 pm. The covers and doors provided by the 3-D printer manufacturer were assembled and installed on all printers by 3:00 pm (see Figure 7), and we continued to monitor particle and TVOC levels throughout the afternoon and overnight.

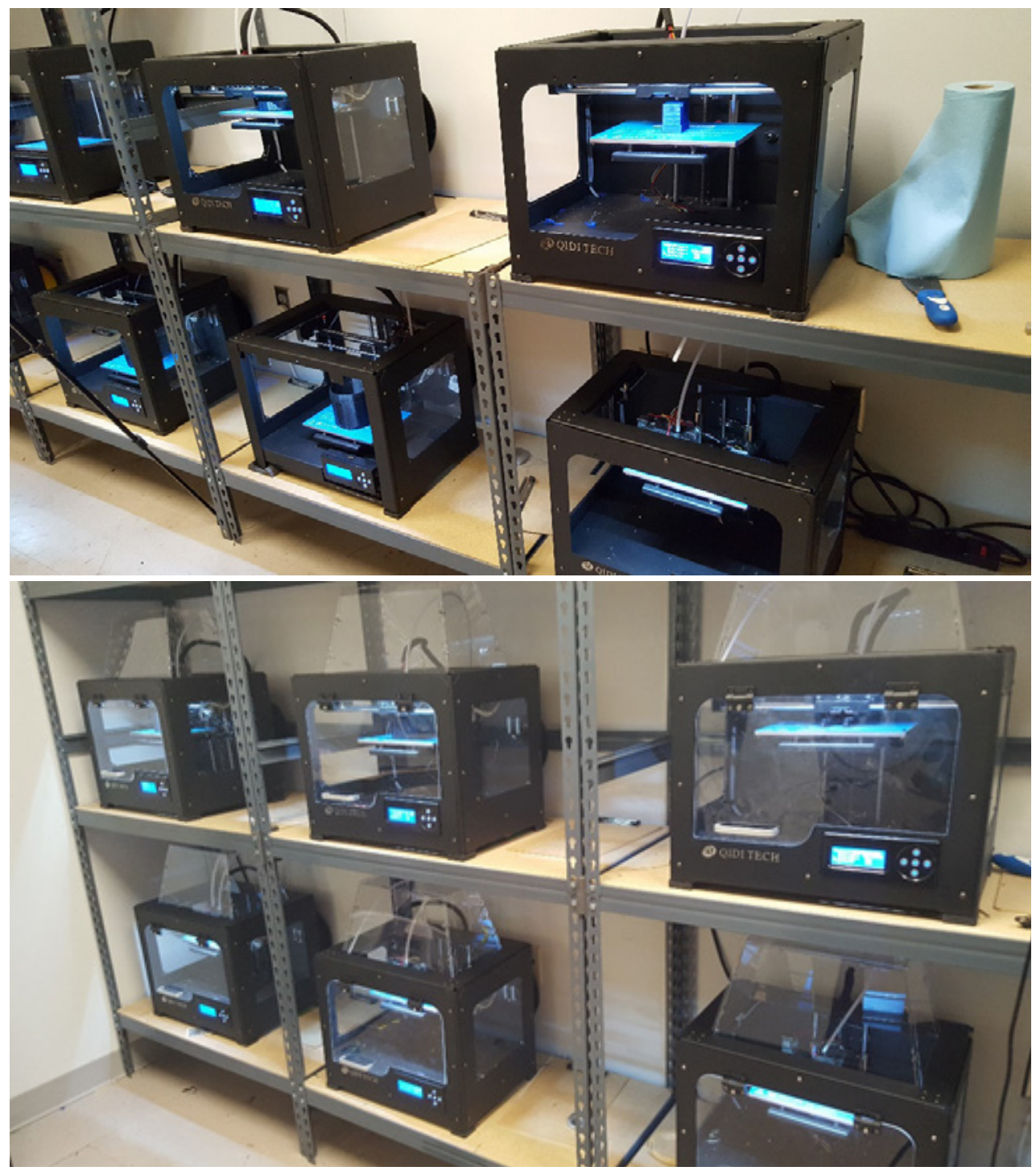

Figure 7. 3-D printers as normally used (top picture) and with the manufacturer-provided plastic covers and doors installed (bottom picture). Photos by NIOSH. 


\section{Particle concentrations in the Print Room}

During the first two hours of monitoring, only 2 to 6 printers were operating; thereafter, all 10 printers were in use. At Location 2, particle concentration reached 275,000 particles $/ \mathrm{cm}^{3}$ of air when all 10 printers were in operation (see Figure 8). Approximately 4 hours after we began monitoring, all manufacturer-provided covers and doors were installed on the 3-D printers (time noted as a vertical line on Figure 8). Soon after installation, particle number concentration at Location 2 decreased, suggesting that the covers and doors helped to reduce particle levels in the Print Room; however, after 60 minutes, levels began to increase again. The same concentration pattern was observed at Location 3.

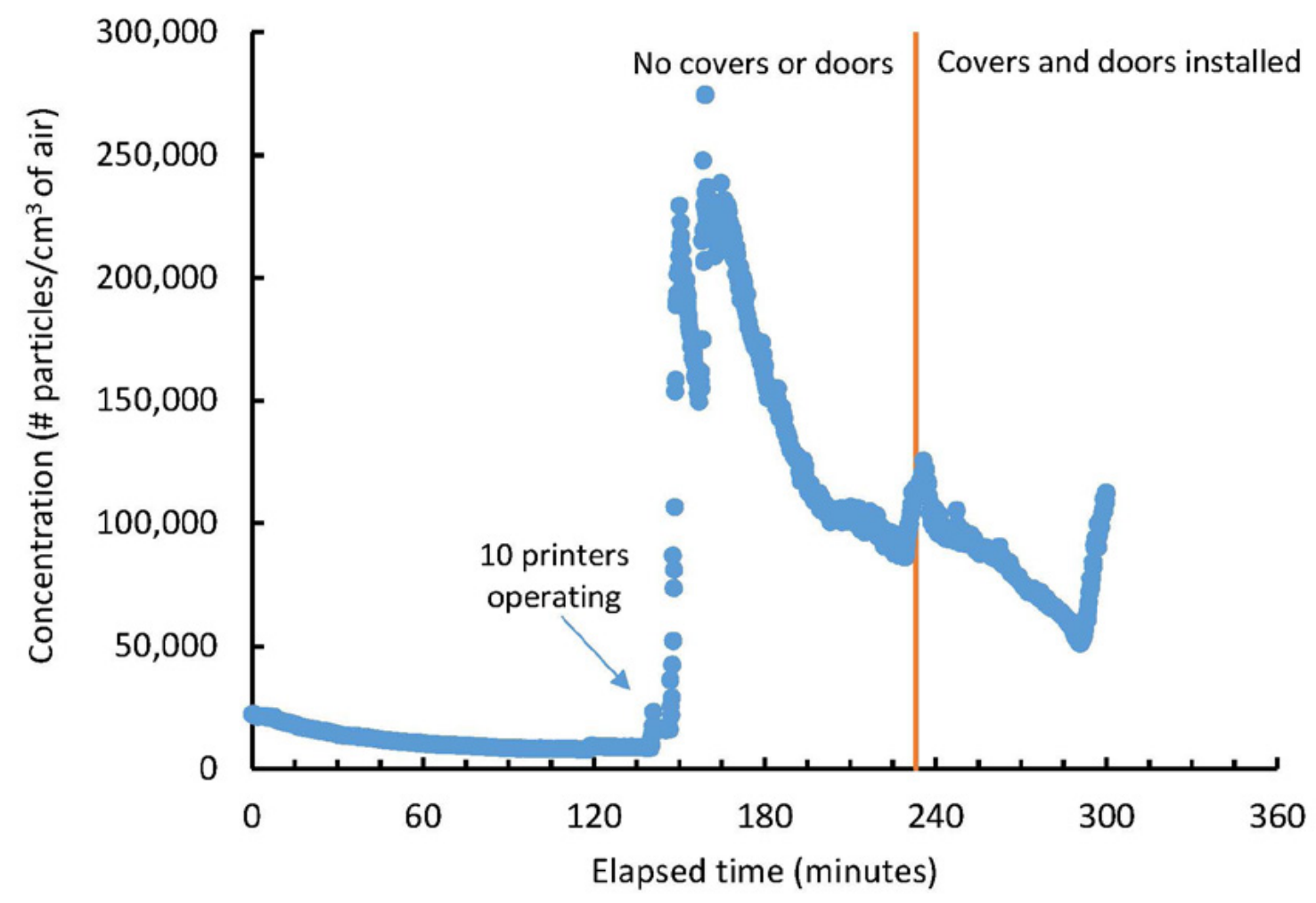

Figure 8. Particle number concentration in the Print Room at Location 2 (adjacent to 3-D printers). The vertical line indicates the time at which all printer covers and doors were installed. 
From visual inspection of the covers and doors, we observed that particles were adhering to the plastic. We determined that this temporary decline in number concentration was because emitted particles were adhering to the plastic covers and doors from electrostatic attraction (see Figure 9). Once this charge effect wore off, particle concentrations at Location 2 began to increase again (shown as rise in concentration at 300 minutes in Figure 8).

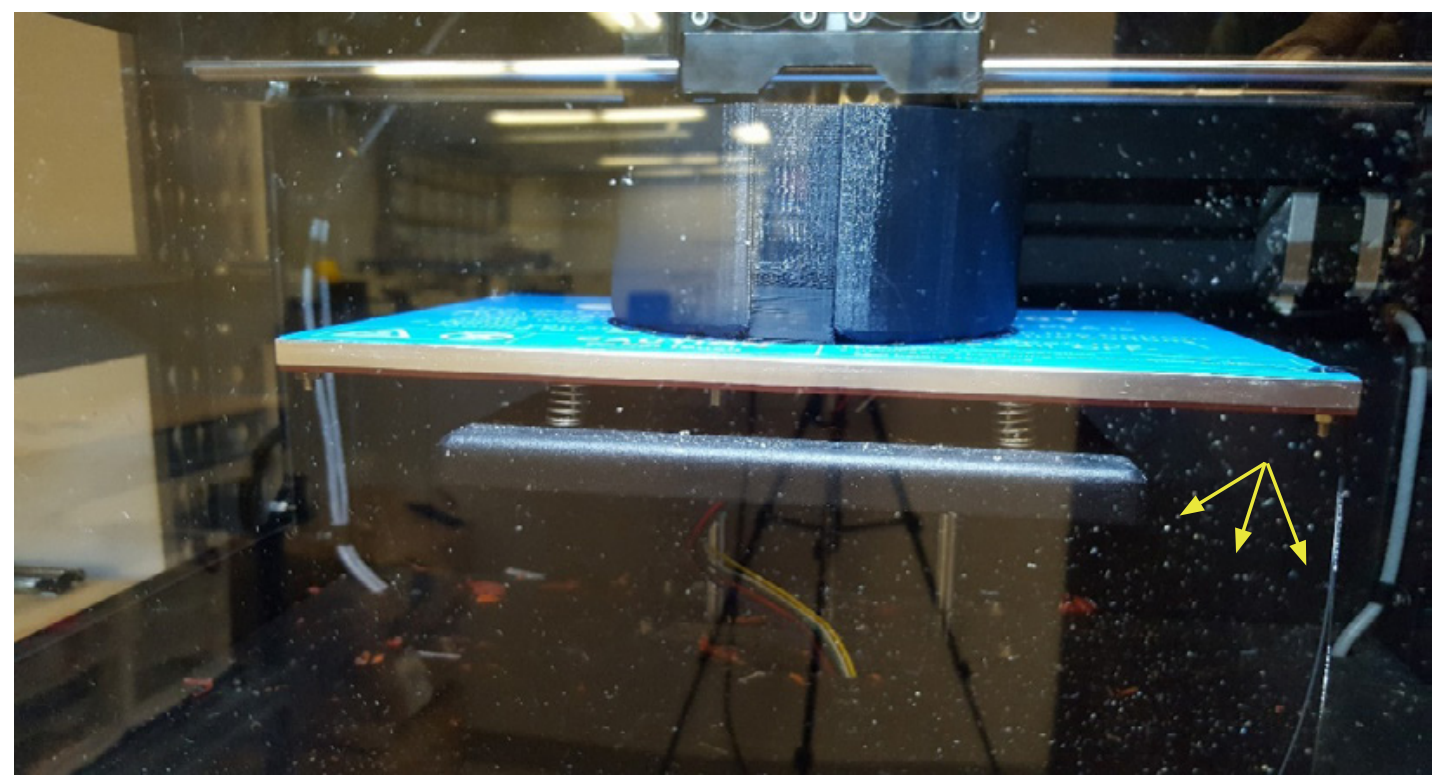

Figure 9. Particle emitted by the 3-D printers initially deposited on the manufacturerprovided covers and doors. Photo by NIOSH. Arrows point to examples of adhered particles.

Approximately 80 minutes after the covers and doors were installed on the printers, we placed the inlet to the $\mathrm{CNC}$ real-time monitor above the 3-D printers near the rear of the cover which was open to the room. Particle number concentration was measured twice for each printer over a period of 60 minutes. In general, the number concentration measured among all printers was between 150,000 particles $/ \mathrm{cm}^{3}$ and 200,000 particles $/ \mathrm{cm}^{3}$ of air which is essentially unchanged from the airborne concentrations measured in the Print Room before the covers and doors were installed (see Figure 8 for comparison).

We also used the CNC monitor to measure the number of particles when the door installed on the printer was opened and when the cover was removed. Particle number concentration was measured twice for each printer (once with the door open, once with the cover removed) over a period of 60 minutes (see Figure 10). For some printers, there was an increase in number concentration when the door was opened or cover removed, though in general the number concentration measured among all printers was about 100,000 particles $/ \mathrm{cm}^{3}$ of air which is similar to the airborne concentrations measured in the Print Room before the covers and doors were installed (see Figure 8 for comparison). 


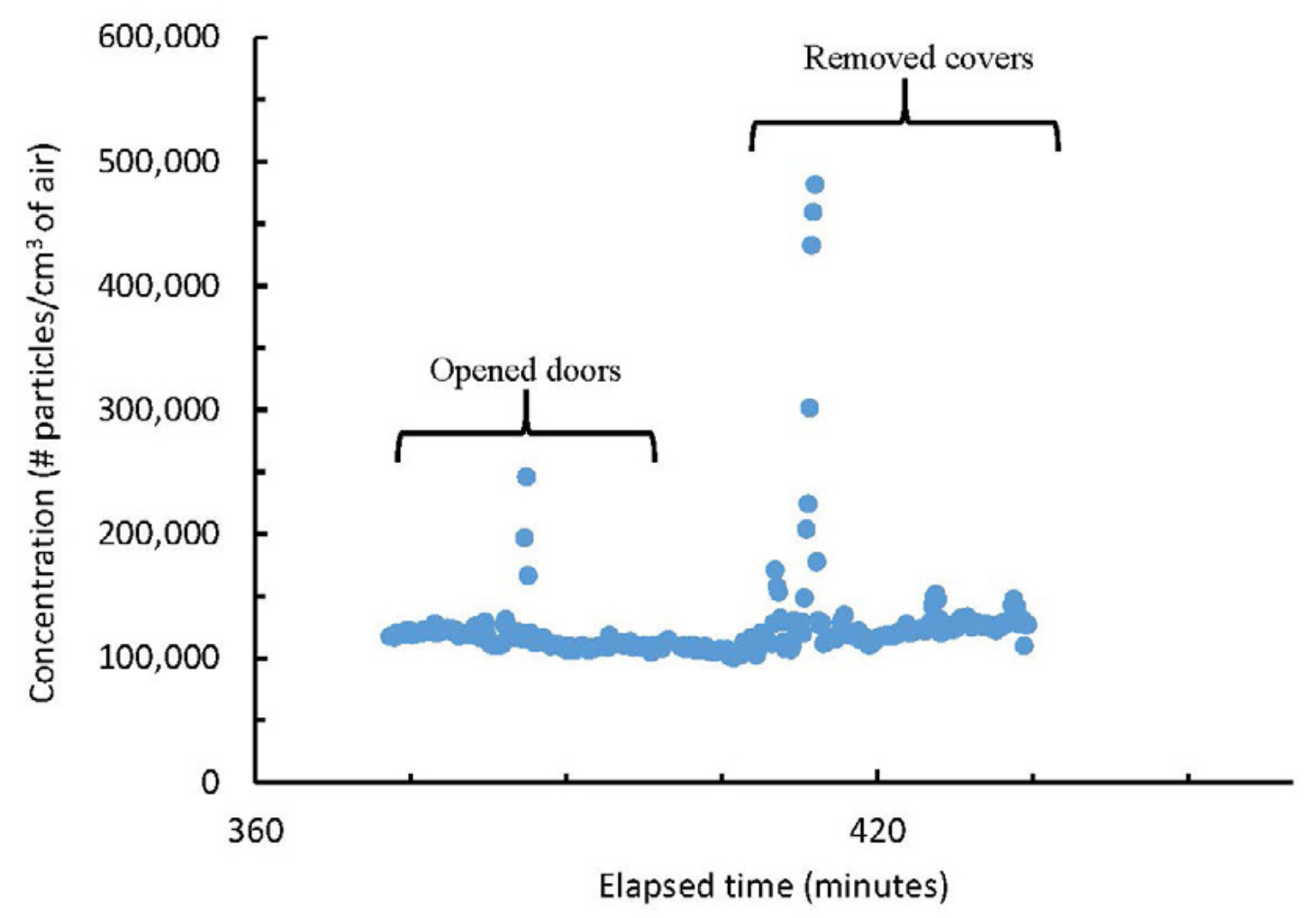

Figure 10. Particle number concentration in the Print Room when printer doors were opened or covers removed.

At Location 2, the concentrations of particles with sizes from $300 \mathrm{~nm}$ to greater than 20 $\mu \mathrm{m}$ were below 100 particles $/ \mathrm{cm}^{3}$ during the day. The particle surface area concentration decreased slightly when the printer covers and doors were installed but increased again shortly thereafter.

Finally, from the NanoScan monitor, the average particle size during the day was $38 \mathrm{~nm}$ which was similar to the average size measured without the doors and covers in place (44 $\mathrm{nm}$ ). The NanoScan measurements followed the same pattern as the CNC instrument (see Figure 8); i.e., there was a temporary decline in particle number concentration just after installation of the covers and doors on the printers, but concentrations soon returned to the same levels as before installation. 
Volatile organic chemical concentrations in the Print Room

The TVOC concentrations at Locations 2 and 3 in the Print Room were similar during the day. As shown in Figure 11, at Location 2, the TVOC concentrations did not appear to be influenced by the printer covers and doors.

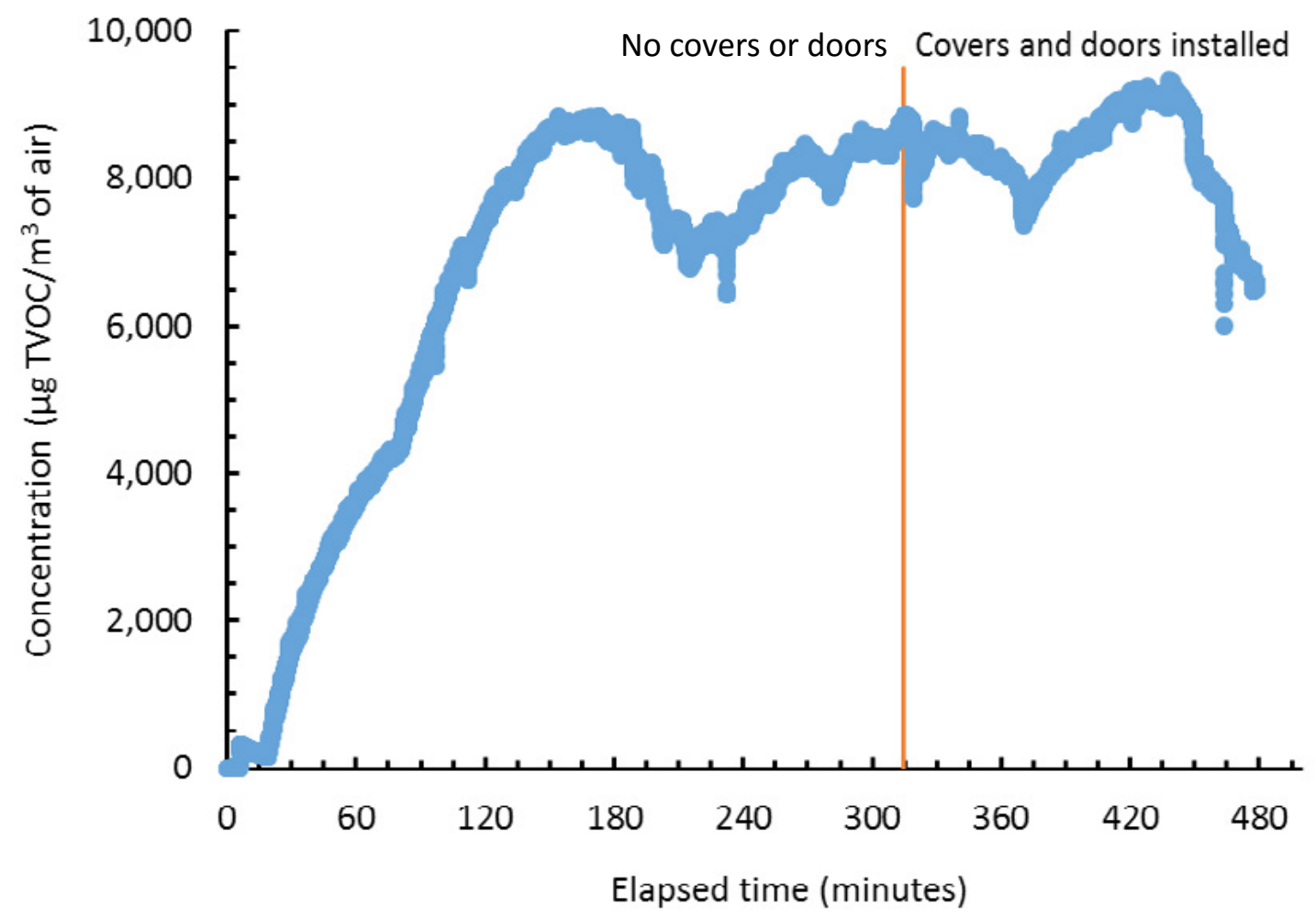

Figure 11. Total volatile organic compound concentration in the Print Room at Location 2 (adjacent to 3-D printers). The vertical line indicates the time at which all printer covers and doors were installed.

\section{Environmental conditions in the Print Room}

Ambient carbon dioxide (range: 600 to $1400 \mathrm{ppm}$ ), carbon monoxide (less than $1 \mathrm{ppm}$ ), and ozone (less than $70 \mathrm{ppb}$ ) concentrations varied only slightly during the day.

\section{Overnight Sampling in the Print Room}

We monitored particles, TVOC concentrations and environmental conditions in the Print Room during the overnight hours (approximately 6:30 pm to 9:00 am) while the 3-D printers operated with the manufacturer-provided doors and covers in place. At Location 2 , the concentration of particles with sizes from 0.3 to greater than $20 \mu \mathrm{m}$ measured by the OPC were below 10 particles $/ \mathrm{cm}^{3}$ throughout the night. Particle surface area concentration measured by the DC decreased during first 2 hours and remained at a steady low concentration overnight. Particle number concentration increased to almost 75,000 particles/ $\mathrm{cm}^{3}$ in the Print Room early on in the night but decreased thereafter to about 2,000 particles/ $\mathrm{cm}^{3}$ by midnight. At about 12:30 am, particle concentration increased to about 16,000 particles $/ \mathrm{cm}^{3}$ and remained elevated for the next 5.5 hours before it decreased to about 1,000 
particles $/ \mathrm{cm}^{3}$ for the remainder of the night. We were not present at the facility during the night, though one possible explanation for the observed pattern is that particle concentrations increased early on in the evening when all printers were in operation but decreased as print jobs were completed. In discussions with the owner, he sometimes comes into the facility late at night to start new print jobs, and this could explain the increase in particle number concentration beginning about 12:30 am.

TVOC concentrations in the Print Room increased to a maximum of about $12,000 \mu \mathrm{g} / \mathrm{m}^{3}$ of air by midnight, and decreased thereafter for the remainder of the night. Ozone concentration remained below $50 \mathrm{ppb}$ overnight. Carbon dioxide was less than 1,400 ppm at all times, and carbon monoxide was less than $1 \mathrm{ppm}$ at all times throughout the night.

Though the observed decreases in particle number and TVOC concentrations throughout the night could be attributed to effectiveness of the printer covers and doors, based on the daytime sampling results (Figures 8 and 11), it is more likely that the declines are because fewer printers operated throughout the night as print jobs were finished.

\section{Objective 5: Effectiveness of a ventilated enclosure to reduce particle and chemical levels in the Print Room}

We collected samples in the Print Room to evaluate whether a ventilated enclosure system with filtration was effective in reducing particle and organic vapor levels in the Print Room. The enclosure was custom-built by NIOSH based on dimensions of the shelving units used to hold the 3-D printers. As shown in Figure 12, the enclosure consisted of acrylic panels for doors that were held closed using magnetic strips. The enclosure was then ventilated using a portable floor fan (Model SS-400-PYT, Sentry Air Systems Inc., Houston, TX) connected to 6-inch diameter flexible hose (Model W1036, Woodstock International Inc., Bellingham, WA) to exhaust the air around the printers. The portable floor fan had a variable speed controller rated to move air at up of 700 cubic feet per minute (CFM) and the air was passed through a high efficiency particulate air (HEPA) filter (Model SS-400-HF, Sentry Air Systems Inc., Houston, TX) and an 8 lb carbon bed (Model SS-408-CF, Sentry Air Systems Inc., Houston, TX) to remove particles and organic vapors, respectively before discharging the air back into the room.

In the morning, seven printers used PLA filaments (black, wood, or yellow). Starting at 1:50 p.m., four printers used ABS filament (white) and six used PLA filament (wood, black, and yellow). Particles and organic chemicals in air were monitored in the Print Room from 9:00 a.m. until 7:00 p.m. (printer covers and doors in place). The enclosure doors were installed on the shelves by 10:15 am but were not closed until 11:45 am. We continued to monitor particle and TVOC levels throughout the afternoon and overnight. 


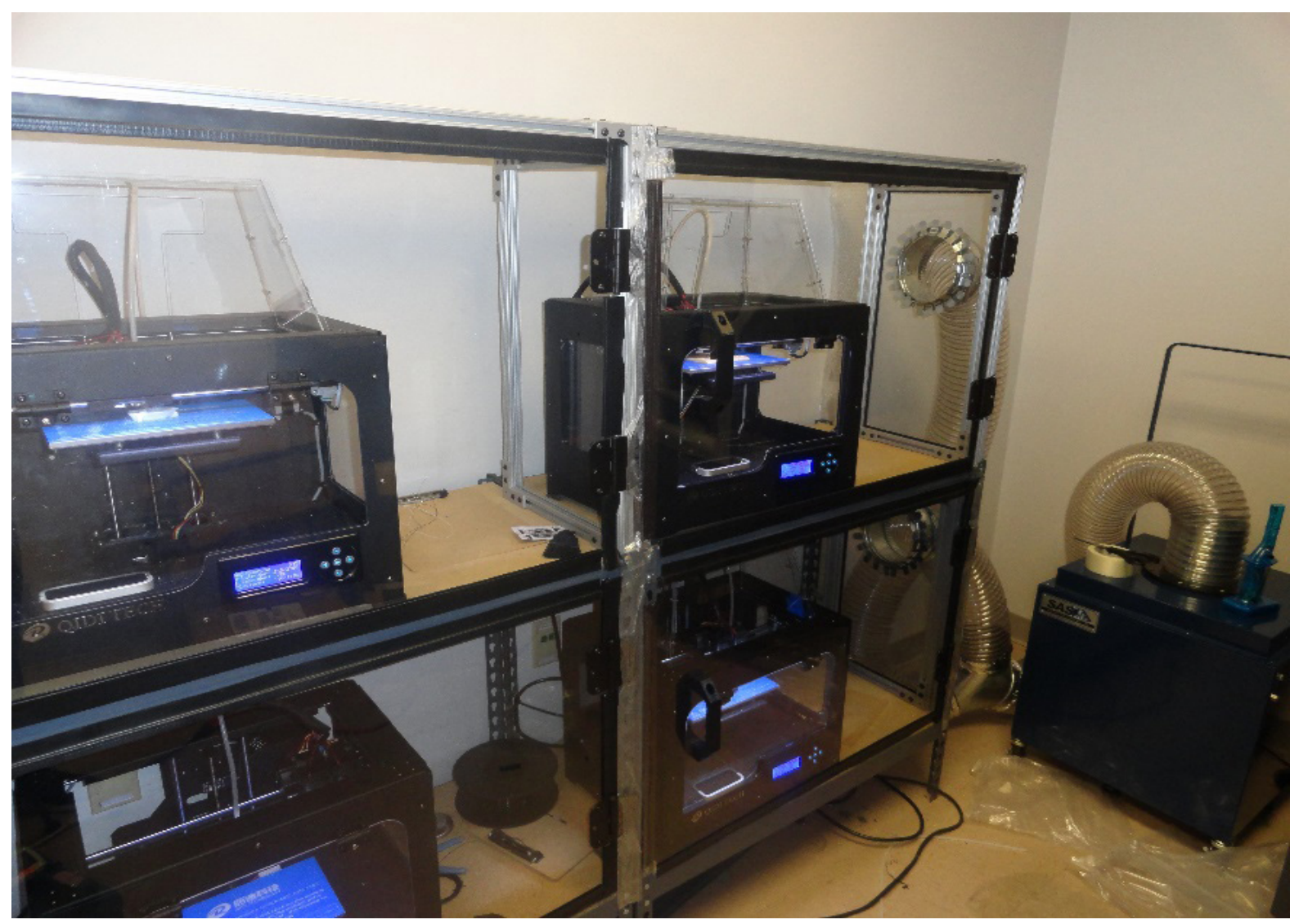

Figure 12. Custom-built ventilated enclosure connected to a floor fan with particle and organic filters. Photo by NIOSH. 


\section{Particle concentrations in the Print Room}

During the day, the enclosure doors were closed, and the fan turned on to ventilate the printers three different times. The first test was from 11:45 am to 12:12 pm, the second test was from 1:50 pm to 2:15 pm, and the third test from 3:22 pm to 4:48 pm. Particle number concentration measured using the OPC remained below $50 / \mathrm{cm}^{3}$ of air throughout the day. Figure 13 is a plot of particle number concentration measured by the NanoScan monitor in the Print Room. Particle concentration in the room decreased each time the enclosure doors were sealed and the fan turned on but rose again as soon as the doors were opened and the fan turned off. The average particle size was $55 \mathrm{~nm}$ which was slightly larger than measured on the previous days in the Print Room. Similar patterns were observed for number concentration measured using the $\mathrm{CNC}$ monitor and surface area concentration measured using the DC at Location 2.

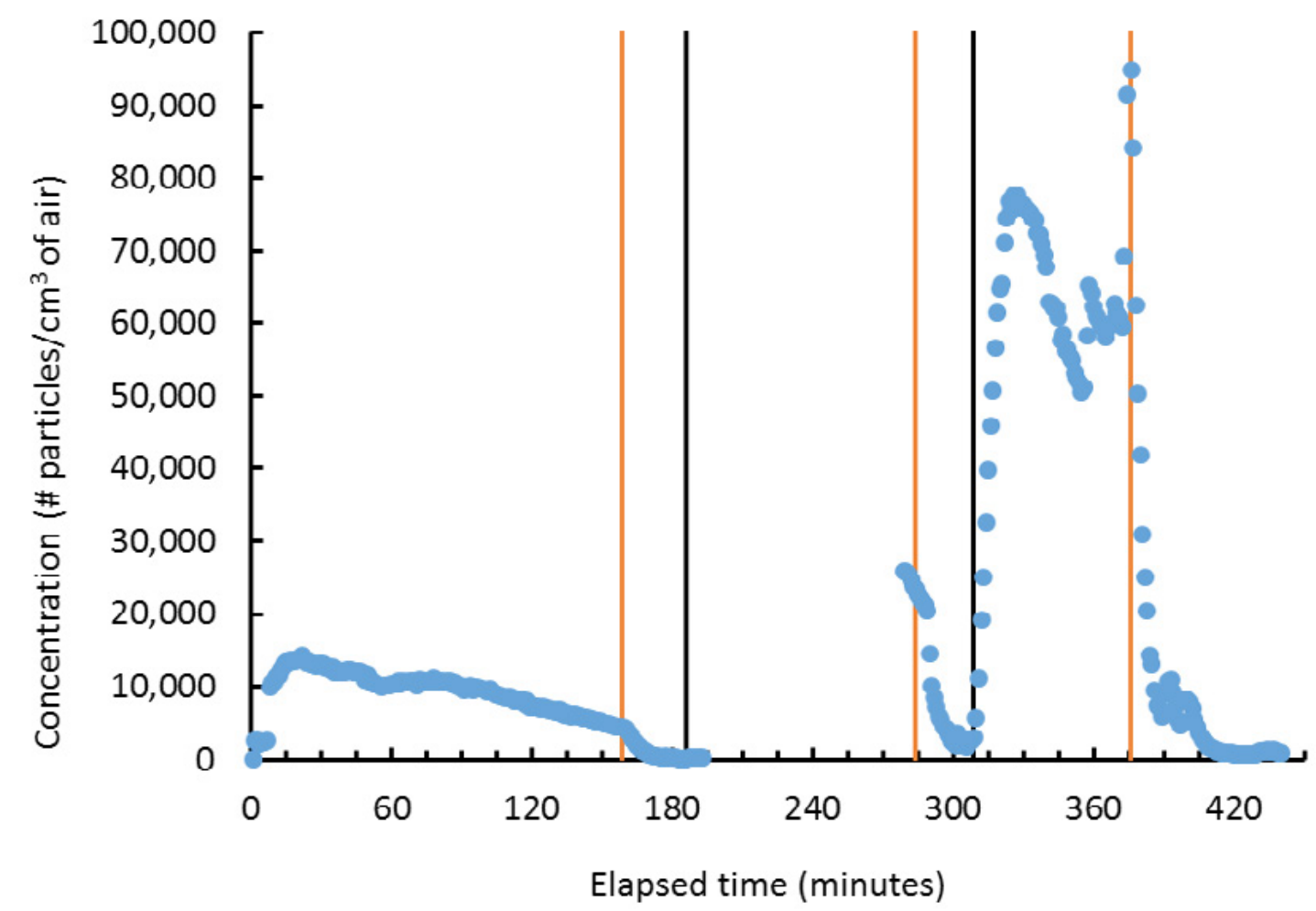

Figure 13. NanoScan measurements of particle number concentration in the Print Room illustrating that levels decreased each time the enclosure doors were sealed and the fan turned on but increased when the enclosure was not used. Vertical red lines indicate when enclosure doors were sealed and the fan turned on. Vertical black lines indicate when doors were opened and the fan turned off. Gap in data from 193 to 279 minutes is when the NanoScan was moved from the Print Room to the High Bay. 
Volatile organic compound concentrations in the Print Room

As shown in Figure 14, TVOC concentrations at Location 2 decreased each time the enclosure doors were closed and the fan turned on to ventilate the printers. TVOC concentrations at Location 3 followed a nearly identical pattern to that shown in Figure 14, and concentration values were very similar. During the day, an intern cleaned the build plate on a 3-D printer using 91\% isopropyl alcohol. The cleaning began at 227 minutes and is noted in Figure 15. The cleaning task lasted about 30 minutes. After cleaning, the alcohol bottle was capped, but the sponge used for cleaning was left beside the printer for about 10 minutes before it was removed from the Print Room. After removing the sponge, there was a visible wet residue on the shelf.

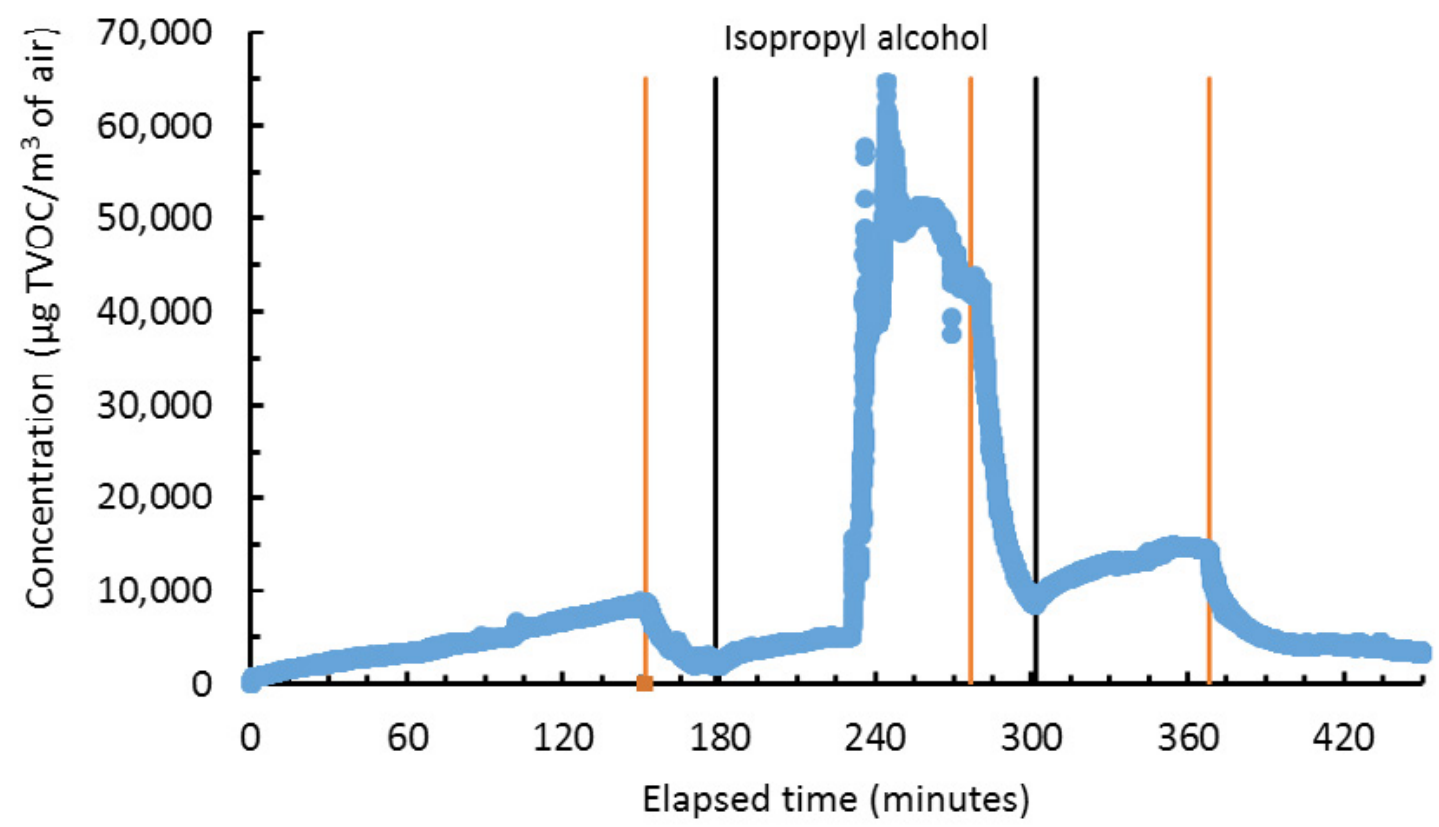

Figure 14. Total volatile organic chemical measurements in the Print Room illustrating the effectiveness of the ventilated enclosure to reduce levels during use. Vertical red lines indicate when enclosure doors were sealed and the fan turned on. Vertical black lines indicate when doors were opened and the fan turned off.

\section{Environmental conditions in the Print Room}

Ozone concentrations were $70 \mathrm{ppb}$ throughout the day. Carbon dioxide concentrations at Locations 2 and 3 were nearly identical and ranged from 1,000 to 1,800 ppm throughout the day. Carbon monoxide levels were less than 4 ppm during the day. Ozone, carbon dioxide, and carbon monoxide concentrations were not influenced by use of the ventilated enclosure.

\section{Overnight Sampling in the Print Room}

We monitored particle number concentration and TVOC concentration inside the enclosure while it was ventilating the printers and outside the enclosure (at Location 2) from approximately 6:00 pm until 9:00 am the next day. Additionally, particle size was measured in the Print Room using the NanoScan monitor. During this time, all 3-D printers were operating with the doors and covers in place. Outside of the enclosure, the particle 
number concentration measured using the CNC monitor reached $142,000 / \mathrm{cm}^{3}$ of air in the Print Room before the doors were sealed and the fan turned on. Within 30 minutes of turning on the fan, the particle number concentration in the room decreased to $418 / \mathrm{cm}^{3}$ of air which is a $99.7 \%$ reduction in particle concentration in the room (see Figure 15). From the NanoScan monitor, the average particle size outside the enclosure was $40 \mathrm{~nm}$, and the reduction of particle number concentration was $99.7 \%$. Inside the enclosure, particle number concentration peaked at $261,000 / \mathrm{cm}^{3}$ of air and decreased to $4,050 / \mathrm{cm}^{3}$ of air within 50 minutes which is a $98.4 \%$ reduction in particle concentration.

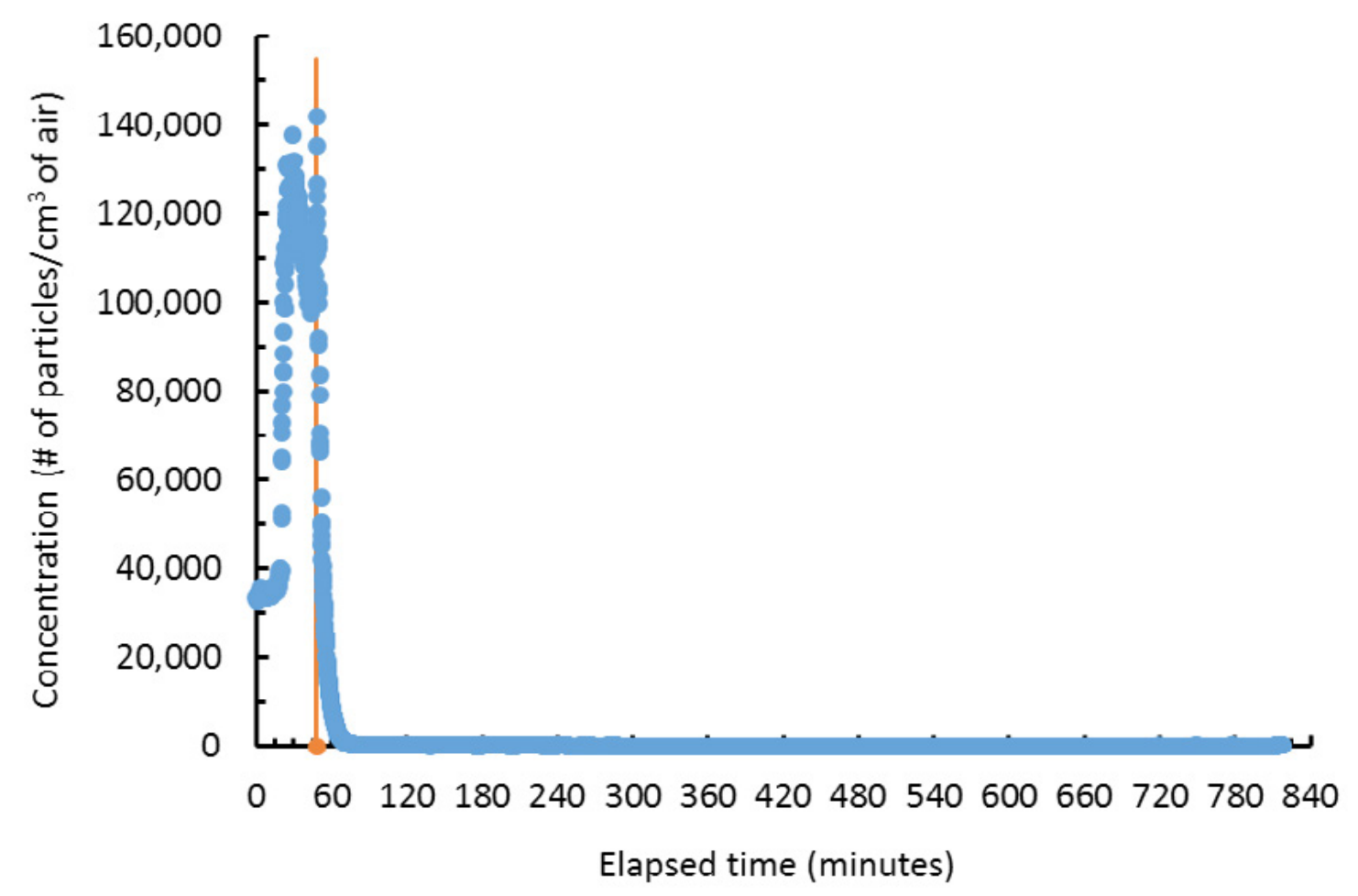

Figure 15. Particle number concentration in the Print Room outside the ventilated enclosure. Vertical line indicates when the enclosure doors were sealed and the fan turned on. 
Figure 16 is a plot of total volatile organic chemical concentration in the Print Room outside the ventilated enclosure. The real-time instrument turned off after monitoring for 4 hours, though during that time, the organic vapor concentration decreased 53.2\%. Inside the enclosure, the real-time instrument ran for 7 hours before turning off and during that time, the organic vapor concentration decreased by $69.5 \%$.

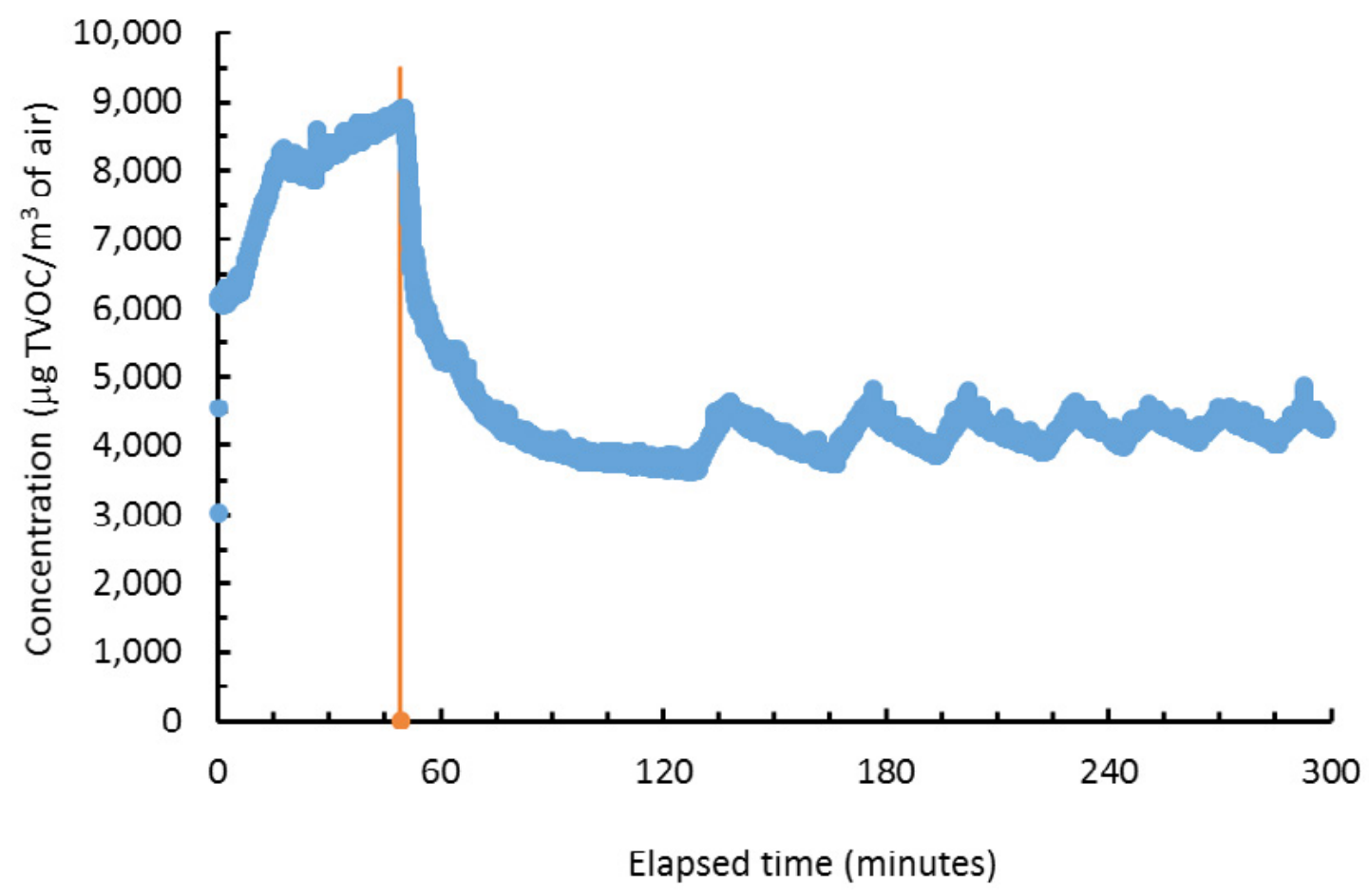

Figure 16. Total volatile organic chemical concentration in the Print Room outside the ventilated enclosure. Vertical line indicates when the enclosure doors were sealed and the fan turned on. 
Objective 6: Evaluation of post-processing tasks and injection molding in the High Bay Post-processing tasks were evaluated on two different days in the High Bay. On the one day, printed objects were briefly sanded, torched using a butane torch, and one object was stained using polyurethane. On the other day, injection molding with ABS pellets and sanding of printed objects were performed.

On the day that sanding, torching, and staining were performed, the tasks collectively lasted approximately 40 minutes. Particle concentrations measured using the OPC and CNC did not differ from background concentrations measured in the High Bay when no tasks were being performed. Average background concentration measured using the NanoScan was about 7200 particles $/ \mathrm{cm}^{3}$ of air, but levels reached 11,000 to 15,000 particles $/ \mathrm{cm}^{3}$ of air during sanding (on the other day that sanding was performed, concentrations reached 30,000 particles $/ \mathrm{cm}^{3}$ of air). Total volatile organic chemical concentrations during background were about 5,000 $\mu \mathrm{g} /$ $\mathrm{m}^{3}$ and fluctuated during post-processing tasks such as light torching. Levels rose to 26,000 $\mu \mathrm{g} / \mathrm{m}^{3}$ during polyurethane staining (see Figure 17 ).

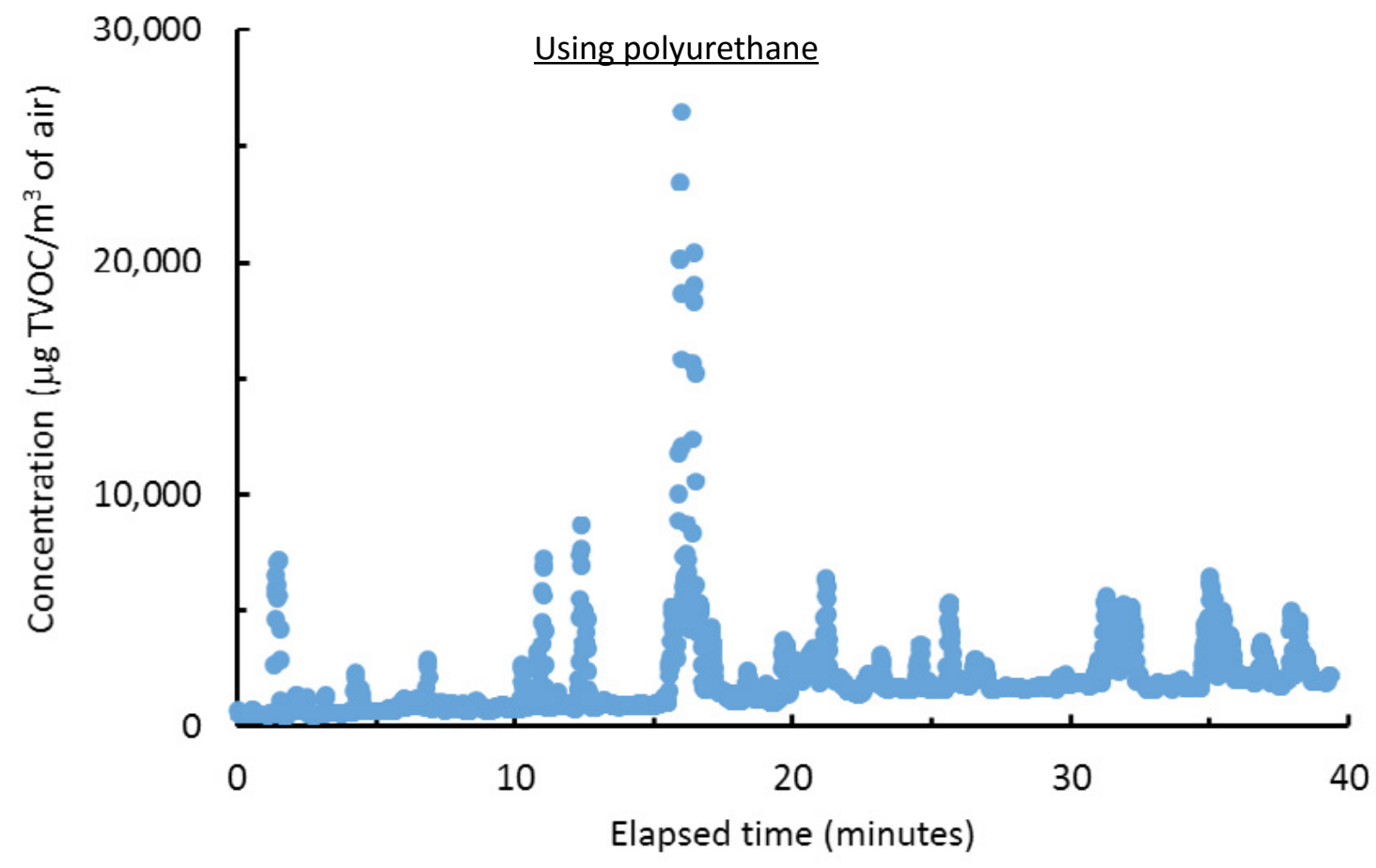

Figure 17. Total volatile organic chemical concentration in the High Bay during postprocessing task. 
Figure 18 is a plot of particle number concentration measured using the NanoScan instrument during injection molding. During warm-up of the injection molding machine, a reservoir containing ABS pellets was heated from $40^{\circ} \mathrm{C}$ to $235^{\circ} \mathrm{C}$, and particle number concentration rapidly increased from an average background level of 3,400 particles $/ \mathrm{cm}^{3}$ to over 134,000 particles $/ \mathrm{cm}^{3}$. Next, the employee injection molded six parts; particle number concentration was increased above background and ranged from 20,000 particles $/ \mathrm{cm}^{3}$ to 26,000 particles/ $\mathrm{cm}^{3}$ during this task. At one point, the employee used a rotary grinding wheel to hone a scraper, and the number concentration increased to over 56,000 particles $/ \mathrm{cm}^{3}$. We observed that during grinding the employee did not use eye protection.

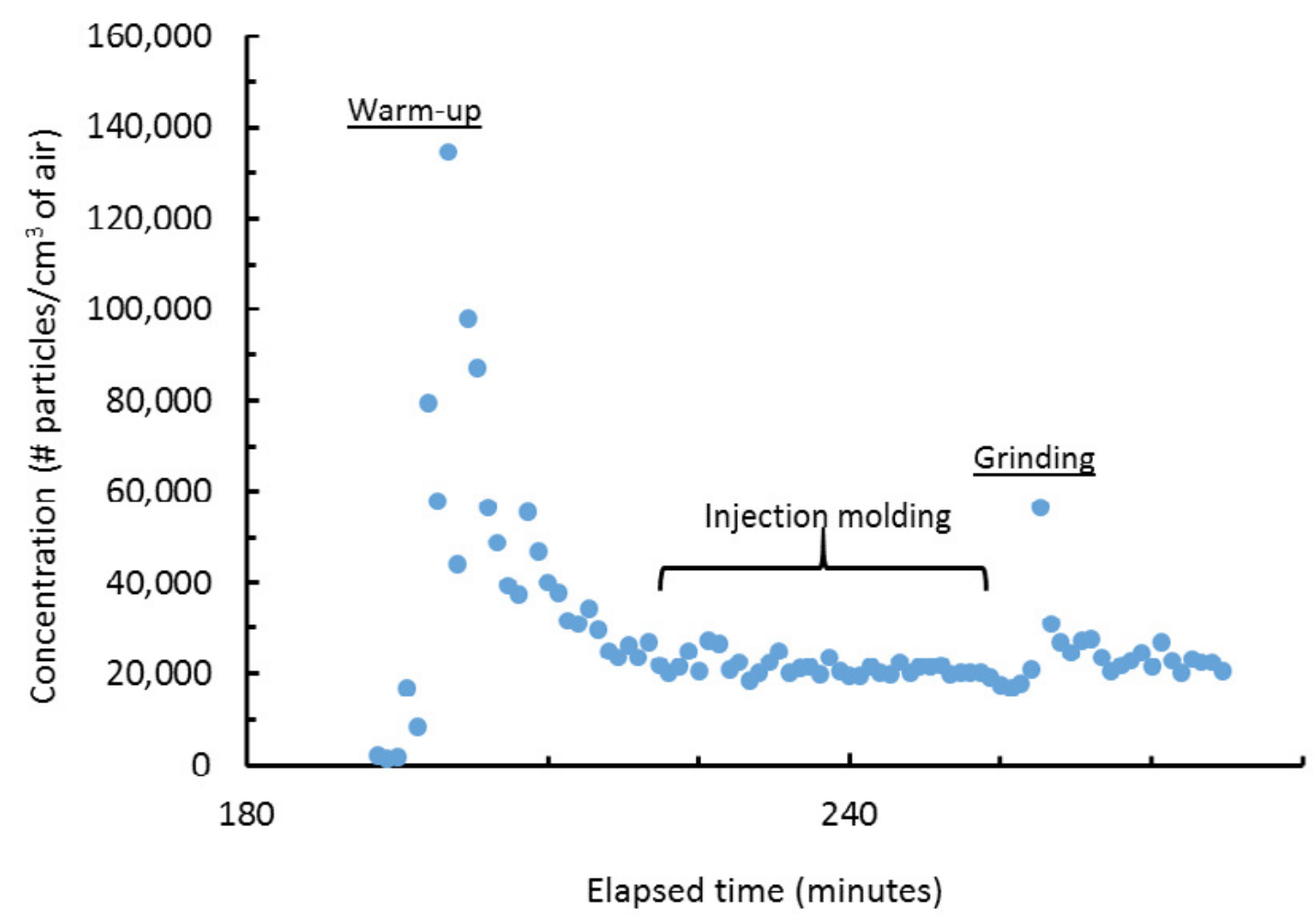

Figure 18. Particle number concentration in the High Bay during injection molding illustrating an increase in particles during warm-up of the molding machine and during grinding.

Organic chemical concentrations were measured using the TVOC monitor and $450 \mathrm{ml}$ evacuated canisters. From the real-time TVOC monitor data, there was no appreciable change in concentration during injection molding or opening a mold; however, concentration increased from about $4,000 \mu \mathrm{g} / \mathrm{m}^{3}$ to over $72,000 \mu \mathrm{g} / \mathrm{m}^{3}$ when ABS pellets were added to the pre-heated hopper. The canister samples were collected over a period of 10 to 15 seconds during specific tasks.

Table 9 summarizes the concentrations of individual VOCs measured using canisters positioned adjacent to the injection molding machine at the start of warm-up $\left(40{ }^{\circ} \mathrm{C}\right)$ and when the machined reached its set temperature $\left(235^{\circ} \mathrm{C}\right)$. Additionally, a canister sample was collected at the opening to the hopper used to feed ABS pellets into the machine 
about 10 minutes after reaching the set temperature. All measurements were corrected for the background concentrations of these chemicals in High Bay room air when tasks were not performed. The identities and concentrations of VOCs were similar during warm-up; however, at the hopper opening more VOCs were identified and at higher concentrations.

Table 9. Concentrations of organic chemicals in the High Bay during warm-up of the injection molding machine

\begin{tabular}{lccc}
\hline \multicolumn{1}{c}{ Chemical } & Start $\left(40^{\circ} \mathrm{C}\right)$ & Set point $\left(235^{\circ} \mathrm{C}\right)$ & Hopper opening \\
\hline Acetaldehyde & & 2.6 & 56.7 \\
Acetone & & & 87.3 \\
Benzene & & 0.1 & 103.2 \\
Diacetyl & & & 0.8 \\
2,3-Hexanedione & 0.5 & 0.6 & \\
2,3-Pentanedione & 19.4 & 15.6 & 33.5 \\
Ethanol & & & 7.6 \\
Ethylbenzene & 524.4 & 530.5 & 2161 \\
Isopropyl Alcohol & & 0.2 & 27.0 \\
Methyl Methacrylate & & & \\
Methylene Chloride & & & 22.7 \\
Styrene & & & 3.9 \\
Toluene & & & 0.7 \\
m,p-Xylene & & & 0.8 \\
o-Xylene & & & \\
\hline
\end{tabular}

Empty cell $=$ chemical not detected 
The molding machine was equipped with a plastic safety shield to prevent a person from placing their hand in the area of the die during molding. Table 10 summarizes the concentrations of individual VOCs measured using canisters positioned inside (samples 1 - 4) and outside (samples 1 - 2) of this shield while molding parts with ABS thermoplastic. Four chemicals were common to samples collected inside and outside of the shield (acetaldehyde, acetone, ethanol, and isopropyl alcohol), but only the measured concentrations of acetone were higher inside the shield. Ten different chemicals were quantified (all at low levels) inside the shield but not detected outside of the shield. Four of these chemicals, ethylbenzene, styrene, m,p-xylene, and o-xylene have been identified in emissions from 3-D printing with ABS filaments [Stefaniak et al. 2017].

Table 10. Concentrations of organic chemicals inside (samples 1 - 4) and outside (samples 5 and 6) of the injection molding machine safety shield

\begin{tabular}{|c|c|c|c|c|c|c|}
\hline \multirow[b]{2}{*}{ Chemical } & \multicolumn{4}{|c|}{ Inside shield } & \multicolumn{2}{|c|}{ Outside shield } \\
\hline & Sample 1 & Sample 2 & Sample 3 & Sample 4 & Sample 5 & Sample 6 \\
\hline Acetaldehyde & 9.0 & & & 6.2 & 33.1 & 0.4 \\
\hline Acetone & & & 46.1 & 6.4 & 9.5 & 6.1 \\
\hline Benzene & 0.6 & & 2.3 & & & \\
\hline Diacetyl & 1.0 & & & & & \\
\hline 2,3-Hexanedione & & & & & & \\
\hline 2,3-Pentanedione & 1.3 & & & & & \\
\hline Ethanol & 24.1 & 16.6 & 22.6 & 28.1 & 23.7 & 39.6 \\
\hline Ethylbenzene & 0.5 & & & & & \\
\hline Isopropyl Alcohol & 1245 & 2700 & 2907 & 14920 & 12060 & 10684 \\
\hline Methyl Methacrylate & 0.4 & & 0.7 & 0.2 & & \\
\hline Methylene Chloride & & & 0.5 & & & \\
\hline Styrene & & & 2.1 & 1.0 & & \\
\hline Toluene & & & 1.0 & & & \\
\hline m,p-Xylene & 0.6 & 0.2 & 0.5 & & & \\
\hline o-Xylene & 0.5 & & & & & \\
\hline
\end{tabular}

Empty cell $=$ not detected 
Objective 7: Employee exposures to volatile organic chemicals

As shown in Figure 19, personal TVOC exposures were usually below $15,000 \mu \mathrm{g} / \mathrm{m}^{3}$ of air on all days and consisted of intermittent periods of relatively low exposure and high exposure. While we did not observe all movements of the Engineer throughout the days, some segments of exposure can be assigned to specific events. For example, at the start of shift on Day 3 the TVOC exposure reached almost $30,000 \mu \mathrm{g} / \mathrm{m}^{3}$, but this occurred when an intern used isopropyl alcohol in the Print Room to clean a printer. Another example is on Day 2, when the Engineer used polyurethane to stain a part in the High Bay which resulted in an exposure to organic chemicals from the coating.

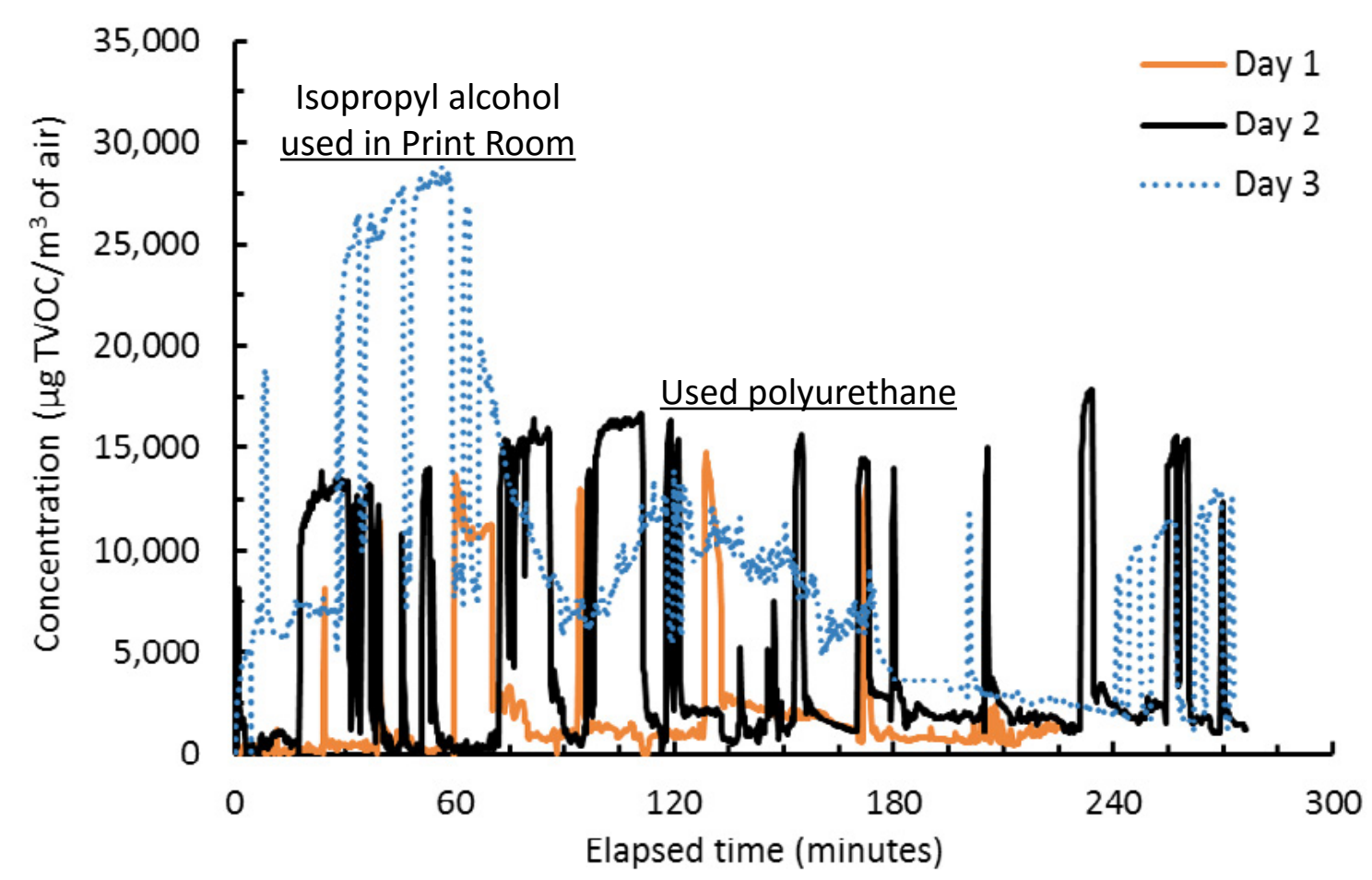

Figure 19. Personal exposures to total volatile organic chemicals during work on three different days.

Table 11 summarizes the identities and concentrations of individual VOCs measured in the breathing zone of the Engineer on each day of the site visit (sample collection ranged from 3 hours to 6.5 hours among days). Acetone and isopropyl alcohol were measured on all days; whereas, acetaldehyde and m,p-xylene were measured on two of three days, and the remaining chemicals quantified on a single day. Among the chemicals identified, the concentration of isopropyl alcohol was the highest on all days. As shown in Figure 19, there was a large increase in TVOC concentrations on Day 3 when isopropyl alcohol was used to clean a printer and that day was also the highest personal exposure to this chemical. Table 11 also includes OELs for the individual chemicals that were measured in the breathing zone of the Engineer. Measured concentrations of all chemicals were well below their corresponding OEL values. Note that if more printers were used in the Print Room or other changes were made to existing work practices, it could increase exposure levels. 
Table 11. Personal exposures to volatile organic chemicals

\begin{tabular}{|c|c|c|c|c|c|c|}
\hline \multirow[b]{2}{*}{ Chemical } & \multicolumn{6}{|c|}{ Concentration (ppm) } \\
\hline & Day 1 & Day 2 & Day 3 & PEL & REL & $\mathrm{TLV}^{\circledR}$ \\
\hline Acetaldehyde & 0.02 & & 0.01 & 200 & Carc $^{\mathrm{a}}$ & $25^{\mathrm{b}}$ \\
\hline Acetone & 0.05 & 0.04 & 0.11 & 1000 & 250 & 250 \\
\hline \multicolumn{7}{|l|}{ Diacetyl } \\
\hline \multicolumn{7}{|l|}{ 2,3-Hexanedione } \\
\hline \multicolumn{7}{|l|}{ 2,3-Pentanedione } \\
\hline Ethanol & & & 0.05 & 1000 & 1000 & $1000^{c}$ \\
\hline Isopropyl Alcohol & 2.6 & 2.0 & 8.8 & 400 & 400 & 200 \\
\hline $\begin{array}{l}\text { Methyl } \\
\text { Methacrylate }\end{array}$ & 0.002 & & & 100 & 100 & 50 \\
\hline Methylene Chloride & & & 0.0004 & 25 & $\mathrm{Carc}^{\mathrm{a}}$ & 50 \\
\hline Toluene & & & 0.0009 & 200 & 100 & 20 \\
\hline m,p-Xylene & 0.002 & & 0.0005 & 100 & 100 & 100 \\
\hline
\end{tabular}

Empty cell $=$ chemical not detected; carc=carcinogen.

a NIOSH recommends that careful consideration should be given to reducing exposures to carcinogens.

${ }^{b}$ Ceiling value that should not be permitted to exceed.

c Short-term exposure limit (STEL)

Employees did not report any respiratory symptoms or other symptoms associated with their work.

\section{Discussion}

During the first two days of our site visit, we collected samples in the Print Room to evaluate particle and chemical emissions from the 3-D printers under normal work conditions with PLA filaments. During both days, objects were printed using white, black, dark blue, yellow, and/ or wood colored PLA filaments. In general, the number concentration of particles ranged from 50,000 particles $/ \mathrm{cm}^{3}$ to 200,000 particles $/ \mathrm{cm}^{3}$ of air (see Figure 2) but increased to 450,000 particles $/ \mathrm{cm}^{3}$ of air when printing when using white PLA filament. We have previously evaluated emissions from 3-D printers in a test chamber and observed that some filament colors emit higher levels of particles than others even when made by the same manufacturer [Yi et al., 2016]. The reason why emissions differ by color is not fully understood at this time but may be due to the additives used for coloring the plastics.

On the day during which objects were printed using both ABS and PLA filaments, there was no appreciable difference in measured emissions compared to using only PLA filaments. In our chamber testing, we have observed higher particle emissions from ABS relative to PLA [Yi et al., 2016]. In an early study of 3-D printers, Stephens and colleagues reported that printing with ABS increased particle levels in a room relative to when operating with PLA filaments [Stephens et al., 2013]. Several VOCs were released during printing with PLA filaments (see Table 2), and the same chemicals were also measured at similar concentrations when printing with ABS filaments (see Table 4). In chamber tests of 3-D printers, we observed that printing 
with ABS but not PLA filaments emitted ethylbenzene, styrene, m,p-xylene, and o-xylene [Stefaniak et al., 2017]. In the Print Room, m,p-xylene was measured when printing with both types of filaments, but o-xylene was only measured when printing with ABS filaments. The absence of styrene in canister samples collected in the Print Room on the day that ABS filaments were used is notable because this chemical is a component of the filament. We only evaluated printing when up to four devices were using ABS filament. If more printers are operated using ABS filament, it could change the types and levels of particle and chemical emissions.

While we were on site, the owner expressed interest in understanding whether emissions from the 3-D printers were escaping from the Print Room and entering the Engineer's Office. As noted in the background section of this report, these rooms were separated by a wall that reached up to a drop ceiling but did not extend to the building ceiling. Based on the differences in particle concentration profiles, particle morphology and chemistry, and organic chemical identities and concentrations between the two locations (see Figure 6 and Tables 5-8), it does not appear that emissions from the 3-D printers were being entrained into the Engineer's Office.

On the second day of our site visit, the plastic covers and doors that were provided by the printer manufacturer were assembled and installed on the 3-D printers. Though it initially appeared that the covers and doors might help to reduce particle (see Figure 8) and chemical (see Figure 11) concentrations in the Print Room, air monitoring after their installation demonstrated that they were not effective. These covers and doors were likely designed and intended to maintain a uniform temperature in the build space. As such, it is important to be aware that their use will not control emissions.

Next, we evaluated whether a custom-built ventilated enclosure (see Figure 12) could reduce particle and chemical emissions in the Print Room. As shown in Figures 13 -16, this enclosure system was highly effective in reducing both particle number and TVOC concentrations in the Print Room. As noted at the beginning of the Results section of this report, there are no occupational exposure limits for particle number concentration or TVOC levels. As such, it is unknown at this time whether the measured levels present a health hazard and whether the reported reductions in contaminant levels are necessary. However, if improved ventilation is desired, one possible consideration would be to route the exhaust from the NIOSH custom enclosure to a fan on the roof at 700 cubic feet per minute to discharge the particle and volatile emissions from the 3-D printing process to the outdoors away from outdoor air intakes. This option would create the need for make-up air to be supplied inside the room but outside of the NIOSH custom enclosure. Also, similar capture effectiveness could be achieved at a lower air flow rate by sealing air gaps around the NIOSH custom enclosure.

We evaluated various post-processing tasks as well as injection molding with ABS pellets. During sanding of 3-D printed objects, particle concentrations were relatively low and released particles were generally on the order of several micrometers. For injection molding, two tasks resulted in elevated emissions: warm-up and adding pellets to the machine hopper. There was no appreciable change in particle or TVOC concentrations during injection molding or opening of the mold. During warm-up, the molding machine reservoir which contained plastic pellets 
was heated from $40{ }^{\circ} \mathrm{C}$ to $235^{\circ} \mathrm{C}$ to melt the plastic and particle number concentration in the High Bay rapidly increased from an average background level of 3,400 particles $/ \mathrm{cm}^{3}$ to over 134,000 particles $/ \mathrm{cm}^{3}$ (see Figure 18).

In a study of 3-D printers, Deng and colleagues determined that particle emissions were mostly from the heating process during warm-up of the extruder nozzle rather than the printing process because the plastic filament undergoes decomposition during the heating period after being loaded into the extruder [Deng et al., 2016]. The heating process for 3-D printers is analogous to the heating process for the injection molding machine. In both devices, thermoplastic (filament in the case of 3-D printers, pellets in the case of injection molding) is heated to melt it. The higher the set-point temperature, the longer the filament must be heated, and the more it will break down to release particles and organic chemicals.

When ABS pellets were added to the pre-heated injection molding machine, TVOC concentrations increased from a background level of about $4,000 \mu \mathrm{g} / \mathrm{m}^{3}$ to over $72,000 \mu \mathrm{g} / \mathrm{m}^{3}$. Analysis of canister samples indicates that the major organic chemical present during injection molding with ABS plastic was isopropyl alcohol; however, low levels of ethylbenzene, styrene, m,p-xylene, and o-xylene were also measured. In chamber tests of 3-D printers using ABS, we have measured these same four chemicals but have not detected them in emissions while printing with PLA filaments [Stefaniak et al. 2017].

Personal exposures to organic chemicals were very low. The highest measured personal exposure was for isopropyl alcohol and this level was more than 20 times below the lowest applicable OEL. It is important to note that while diacetyl, 2,3-pentanedione and 2,3-hexanedione were identified in general area air samples, indicating a potential exposure risk, none of these carbonyl compounds were detected on personal exposure samples. Exposures to organic chemicals cannot be attributed solely to 3-D printing because the Engineer is mobile and spends time in the Print Room, Engineer's Office, and the High Bay. As demonstrated in Figure 19, some exposure can be attributed to cleaning printers or postprocessing tasks.

Finally, it is important to note that the measured personal exposures and workplace emissions are a reflection of current working conditions. It is known from existing research that 3-D printer- and filament-related factors influence emissions [Yi et al., 2016; Stefaniak et al., 2016]. Changes in printer parameters such as the thickness of each printed layer, the extrusion temperature, build plate temperature, filament feed rate, and number of printers can all influence emissions. Filament properties such as ingredients, inclusion of additives, type (for example, ABS or PLA), and color can also influence emissions. As such, if changes are made to how desktop 3-D printing is performed or which filaments are used or if the industrial-scale 3-D printer is used, they will likely change the emissions and personal exposures.

\section{Conclusions}

Employees were exposed to detectable levels of organic chemicals in the air while working 
in this facility, though not all exposures were from 3-D printing. All measured personal exposures to organic chemicals were well below applicable OSHA PELs. We recommend that if changes are made to the existing process or if the industrial-scale 3-D printer is put into use, the employer should reassess personal exposures and emissions. Employees should be aware of how specific tasks influence exposures and that changes in how they perform their work could increase exposure. At this time, we do not recommend any controls to lower exposures as they are already well-below established regulatory limits. Similarly, at this time we do not recommend the need to lower total particle number and TVOC concentrations as there is no available guidance on an appropriate level; however, as shown in this report, these measurements are useful for understanding how various printing parameters and work tasks can influence the amount of particles and chemicals that get into air. Additionally, the realtime measurements in this report can be used as a reference to which particle and chemical levels can be compared if operations are expanded or modified in the future. It is important to note that 3-D printing has not been thoroughly evaluated to determine its safety. As such, new information may become available in the future which may change our current perspective on the necessity of controls.

\section{Recommendations}

On the basis of our findings, we recommend the actions listed below. We encourage this 3-D printing facility to use a labor-management health and safety committee or working group to discuss our recommendations and develop an action plan.

Our recommendations are based on an approach known as the hierarchy of controls. This approach groups actions by their likely effectiveness in reducing or removing hazards. In most cases, the preferred approach is to eliminate hazardous materials or processes and install engineering controls to reduce exposure or shield employees. Until such controls are in place, or if they are not effective or feasible, administrative measures and personal protective equipment may be needed.

\section{Elimination and Substitution}

Eliminating or substituting hazardous processes or materials reduces hazards and protects employees more effectively than other approaches. Prevention through design, considering elimination or substitution when designing or developing a project, reduces the need for additional controls in the future.

1. Based on our measurement results, we do not have any recommendations to eliminate or substitute filament materials at this time; however, if changes are made to the 3-D printing process or which filaments are used it would be prudent to reassess emissions and personal exposures. 


\section{Engineering Controls}

Engineering controls reduce employees' exposures by removing the hazard from the process or by placing a barrier between the hazard and the employee. Engineering controls protect employees effectively without placing primary responsibility of implementation on the employee.

1. At this time, we do not recommend any controls to lower chemical exposures as they are already well-below established regulatory limits. Similarly, at this time we do not recommend the need to lower total particle and TVOC concentrations.

2. If the employer wanted to utilize a ventilated enclosure such as the one we tested, the details of its construction are provided in this report.

\section{Administrative Controls}

The term administrative controls refers to employer-dictated work practices and policies to reduce or prevent hazardous exposures. Their effectiveness depends on employer commitment and employee acceptance. Regular monitoring and reinforcement are necessary to ensure that policies and procedures are followed consistently.

1. At this facility, it is normal practice to keep the Print Room door closed, and we recommend continuing this practice. Additionally, we recommend that employees close the door to the Engineer's Office when performing tasks that generate dusts and organic chemicals in the High Bay.

\section{Personal Protective Equipment}

Personal protective equipment is the least effective means for controlling hazardous exposures. Proper use of personal protective equipment requires a comprehensive program and a high level of employee involvement and commitment. The right personal protective equipment must be chosen for each hazard. Supporting programs such as training, changeout schedules, and medical assessment may be needed. Personal protective equipment should not be the sole method for controlling hazardous exposures. Rather, personal protective equipment should be used until effective engineering and administrative controls are in place.

1. We observed that during grinding the employee did not use eye protection and recommend the use of appropriate protective eyewear when performing this task. 


\section{References}

ACGIH (American Conference of Governmental Industrial Hygienist) [2016]. 2016 TLVs ${ }^{\circledR}$ and BEIs ${ }^{\circledR}$ : threshold limit values for chemical substances and physical agents and biological exposure indices. Cincinnati, OH: American Conference of Governmental Industrial Hygienists.

AIHA (American Industrial Hygiene Association) [2011]. AIHA 2012 Emergency response planning guidelines (ERPG) \& workplace environmental exposure levels (WEEL) handbook. Fairfax, VA: American Industrial Hygiene Association.

CFR. Code of Federal Regulations. Washington, DC: U.S. Government Printing Office, Office of the Federal Register.

Deng Y, Cao SJ, Chen A, Guo Y [2016]. The impact of manufacturing parameters on submicron particle emissions from a desktop 3D printer in the perspective of emission reduction. Build Environ 104:311-319. Available at: https://doi.org/10.1016/j. buildenv.2016.05.021. Date accessed: August 2017.

Lebouf RF, Stefaniak AB, Virji MA [2012]. Validation of evacuated canisters for sampling volatile organic compounds in healthcare settings. J Environ Monit 14(3):977-983. Available at: http://dx.doi.org/10.1039/c2em10896h. Date accessed: August 2017.

NIOSH [2010]. NIOSH pocket guide to chemical hazards. Cincinnati, OH: U.S. Department of Health and Human Services, Centers for Disease Control and Prevention, National Institute for Occupational Safety and Health, DHHS (NIOSH) Publication No. 2010-168c Available at: http://www.cdc.gov/niosh/npg/. Date accessed: August 2017.

NIOSH [2016]. Criteria for a recommended standard: occupational exposure to diacetyl and 2,3-pentanedione. Cincinnati, OH: U.S. Department of Health and Human Resources, Centers for Disease Control and Prevention, National Institute for Occupational Safety and Health, DHHS (NIOSH) Publication No. 2016-11. Available at: https:/www.cdc.gov/niosh/ docs/2016-111/pdfs/2016-111-all.pdf. Date accessed August 2017.

OSHA [2016]. Permissible exposure limits - annotated tables. Available at: https://www. osha.gov/dsg/annotated-pels/index.html. Date accessed: August 2017.

Stefaniak AB, LeBouf RF, Yi J, Ham J, Nurkewicz T, Schwegler-Berry DE, Chen BT, Wells JR, Duling MG, Lawrence RB, Martin Jr. SB, Johnson AR, Virji MA [2017]. Characterization of chemical contaminants generated by a desktop fused deposition modeling 3-dimensional printer. J Occup Environ Hygiene 14(7):540-550. Available at: http://dx.doi.or g/10.1080/15459624.2017.1302589. Date accessed: August 2017. 
Stephens B, Azimi P, El Orch Z, Ramos T [2013]. Ultrafine particle emissions from desktop 3D printers. Atmos Environ 79:334-339. Available at: https://doi.org/10.1016/j. atmosenv.2013.06.050. Date accessed: August 2017.

Yi J, LeBouf RF, Duling MG, Nurkiewicz T, Chen BT, Schwegler-Berry D, Virji MA, Stefaniak AB [2016]. Emission of particulate matter from a desktop three-dimensional (3-D) printer. J Toxicol Environ Health Part A. 79(11):453-465. Available at: http://dx.doi.org/10.10 80/15287394.2016.1166467. Date accessed: August 2017. 
This page left intentionally blank 
Keywords: NAICS 323111 Texas, 3D printer, nanoparticles, volatile organic compounds, acrylonitrile butadiene styrene, poly lactic acid. 
The Health Hazard Evaluation Program investigates possible health hazards in the workplace under the authority of the Occupational Safety and Health Act of 1970 (29 U.S.C. § 669(a) (6)). The Health Hazard Evaluation Program also provides, upon request, technical assistance to federal, state, and local agencies to investigate occupational health hazards and to prevent occupational disease or injury. Regulations guiding the Program can be found in Title 42, Code of Federal Regulations, Part 85; Requests for Health Hazard Evaluations (42 CPR Part 85).

\section{Disclaimer}

The recommendations in this report are made on the basis of the findings at the workplace evaluated and may not be applicable to other workplaces.

Mention of any company or product in this report does not constitute endorsement by the National Institute for Occupational Safety and Health (NIOSH).

Citations to Web sites external to NIOSH do not constitute NIOSH endorsement of the sponsoring organizations or their programs or products. NIOSH is not responsible for the content of these Web sites. All Web addresses referenced in this document were accessible as of the publication date.

\section{Acknowledgments}

Desktop Publisher: Tia McClelland

Data Analysis Support: Brian Tift

Laboratory Support: Ryan LeBouf, Dru Burns

Site Visit Team Members: Duane Hammond, Alyson Johnson, Aleksandr Stefaniak

\section{Availability of Report}

Copies of this report have been sent to the employer, employees, and union at the facility. The state and local health department and the Occupational Safety and Health Administration Regional Office have also received a copy. This report is not copyrighted and may be freely reproduced.

This report is available at http://www.cdc.gov/niosh/hhe/reports/pdfs/2017-0059-3291.pdf.

All other HHE Reports may be found at http://www2a.cdc.gov/hhe/search.asp

\section{Recommended citation for this report:}

$\mathrm{NIOSH}$ [2017]. Health hazard evaluation report: evaluation of 3-D printer emissions and personal exposures at a manufacturing workplace. By Stefaniak AB, Hammond D, Johnson AR, Knepp AK, LeBouf RF. Morgantown, WV: U.S. Department of Health and Human Services, Centers for Disease Control and Prevention, National Institute for Occupational Safety and Health, NIOSH HHE Report No. 2017-0059-3291 
Delivering on the Nation's promise:

Safety and health at work for all people through research and prevention

To receive documents or other information about occupational safety and health topics, contact NIOSH

Telephone: 1-800-CDC-INFO (1-800-232-4636)

TTY: 1-888-232-6348

email: cdcinfo@cdc.gov

or visit the NIOSH website at http://www.cdc.gov/niosh

SAFER • HEALTHIER $\cdot$ PEOPLE $^{\text {TM }}$ 